\title{
Production performance and survivability of six dual-purpose breeds of chicken under smallholder farmers' management practices in Nigeria
}

\author{
Folasade Olubukola Ajayi ${ }^{1}$, Oladeji Bamidele ${ }^{2}$, Waheed Akinola Hassan ${ }^{3}$, Uduak Ogundu ${ }^{4}$, \\ Abdulmojeed Yakubu ${ }^{5}$, Olayinka Olubunmi Alabi ${ }^{6}$, Oludayo Michael Akinsola ${ }^{7}$, \\ Emmanuel Babafunso Sonaiya ${ }^{2}$, and Oluwafunmilayo Ayoka Adebambo ${ }^{8}$ \\ ${ }^{1}$ Department of Animal Science, University of Port-Harcourt, Rivers State, Nigeria \\ ${ }^{2}$ African Chicken Genetic Gains Project National Secretariat, Department of Animal Science, \\ Obafemi Awolowo University, Ile-Ife, Osun State, Nigeria \\ ${ }^{3}$ Department of Animal Science, Usmanu Danfodiyo University, Sokoto, Sokoto State, Nigeria \\ ${ }^{4}$ Department of Animal Science, Federal University of Technology, Owerri, Imo State, Nigeria \\ ${ }^{5}$ Department of Animal Science, Faculty of Agriculture, Nasarawa State University, \\ Keffi, Shabu-Lafia Campus Lafia, Nasarawa State, Nigeria \\ ${ }^{6}$ Department of Animal Science, Landmark University, Omu-Aran, Kwara State, Nigeria \\ ${ }^{7}$ Department of Theriogenology and Production, University of Jos, Jos, Plateau State, Nigeria \\ ${ }^{8}$ Department of Animal Breeding and Genetics, Federal University of Agriculture, \\ Abeokuta, Ogun State, Nigeria
}

Correspondence: Folasade Olubukola Ajayi (folajayi@gmail.com)

Received: 6 December 2019 - Accepted: 16 September 2020 - Published: 12 November 2020

\begin{abstract}
Chickens kept under free-range, backyard or semi-intensive systems in the developing countries have more diverse use and benefits to rural households. Their use varies from region to region and from community to community within a region. The study investigated growth, laying performance and survivability of six improved dual-purpose breeds in five agroecologies of Nigeria represented by the following states: Kebbi (Sudan savanna/northern Guinea savanna); Kwara (northern Guinea savanna/southern Guinea savanna); Nasarawa (southern Guinea savanna/derived savanna); Imo (lowland rainforest/swamp); and Rivers (freshwater swamp/mangrove swamp). On-farm data were obtained from 2100 smallholder poultry farmers that received an average of 30 birds (mixed sexes) of any one of the following dual-purpose breeds (Fulani, FUNAAB Alpha, Kuroiler, Noiler, Sasso and Shika-Brown) randomly allocated to them. The farmers used the backyard, scavenging system of management. Body weight and mortality records for cocks were taken for 18 weeks, while body weight, mortality, egg production and egg weight data were collected for hens up to 72 weeks. Compared with the local cocks (680 g), Kuroiler (1391 g), Sasso (1398 g) and Noiler (1461 g) had over $200 \%$ body weight at 18 weeks. Hen day egg production (HDEP) was higher in Shika-Brown (45.9\%), FUNAAB Alpha (45.8\%) and Kuroiler (45.7\%) compared with the other breeds. Fulani, FUNAAB Alpha and Shika-Brown had higher survivabilities $(p<0.05)$ than Noiler, Sasso and Kuroiler. Ranking of the breeds for growth, laying performance and survivability was as follows: Shika-Brown/Sasso $>$ FUNAAB Alpha/Noiler $>$ Kuroiler $>$ Fulani. The performance of the breeds was significantly $(p<0.05)$ influenced by the agroecologies. The cock body weights for Fulani $(1121.1 \mathrm{~g})$, FUNAAB Alpha (1502.4 g) and Noiler (1459.2 g) were highest in Kebbi, while for Kuroiler (1561.0 g), Sasso $(1695.9 \mathrm{~g})$ and Shika-Brown $(1131.6 \mathrm{~g})$ cock body weights were highest in Imo. Across the states, Imo had the highest HDEP $(62.8 \%)$. Overall, the lowland rainforest/ freshwater swamp agroecologies supported the highest production performance of the breeds.
\end{abstract}




\section{Introduction}

In many developing countries chickens are reared under the free-range, backyard or semi-intensive system as a means of improving the livelihood of the people (Sonaiya, 1990, 2007; Kitalyi, 1998; Guèye, 2000; Kryger et al., 2010; Billah et al., 2013; Yusuf et al., 2014; Alemayehu et al., 2018). A major challenge of smallholder chicken production is the use of local genotypes with a small body size, which offer poor feed quantity and quality resulting in low egg and meat output and high mortality (Yakubu et al., 2007; Mellesse, 2014; Ajayi and Agaviezor, 2016; Sankhyan and Thakur, 2018). A knowledge of the production performance of traits of economic importance is required for formulation of breeding plans aimed at improving the livelihoods of smallholder chicken farmers (Yakubu et al., 2019). Improving genetic potentials of smallholder chicken requires testing different breeds in two or more environments in order to determine the magnitude of genotype $\times$ environment interaction (Falconer and Mckay, 1996; Nauta, 2009).

In order to improve the productivity of chicken of smallholder farmers in sub-Saharan Africa, two foreign-sourced tropically adapted breeds from India (Kuroiler) and France (Sasso) and four locally sourced breeds (FUNAAB Alpha, Noiler, Shika-Brown and Fulani) developed in Nigeria (Bamidele et al., 2019) were tested on-farm for growth, egg production and survivability in five agroecological zones in Nigeria. The study was carried out under the African Chicken Genetic Gains (ACGG) project in Nigeria with the aim of guiding decisions on the choice of appropriate smallholder chicken breeds.

\section{Materials and methods}

\subsection{Description of study area}

On-farm data were collected between August 2016 and August 2018 in five different agroecological zones represented by five states: Kebbi (Sudan savanna/northern Guinea savanna), Kwara (northern Guinea savanna/southern Guinea savanna), Nasarawa (southern Guinea savanna/derived savanna), Imo (lowland rainforest/swamp) and Rivers (freshwater swamp/mangrove swamp) states. The climatic conditions of the five agroecologies were as described by Yakubu et al. (2019). Kebbi and Nasarawa had similar average temperature of $28^{\circ} \mathrm{C}$, while average temperatures in Imo, Kwara and Rivers ranged between 26.4 and $26.8^{\circ} \mathrm{C}$. Relative humidity was $47.4 \%, 74.0 \%, 74.4 \%, 80.0 \%$ and $83.4 \%$, respectively, for Kebbi, Nasarawa, Kwara, Imo and Rivers. Annual rainfall in the five zones also followed the same pattern as the relative humidity. The values are 809, 1169, 1217, 2219 and $2708 \mathrm{~mm}$, respectively, for Kebbi, Nasarawa, Kwara, Imo and Rivers.
In each of the three senatorial districts of each state, two local government areas (LGAs) were randomly selected (i.e. six LGAs) and two villages were randomly selected per LGA giving 12 villages per state and 60 villages in all. A total of 2100 smallholder farmers were randomly selected from the five states at 420 farmers per state. The population of chickens distributed according to breed and agroecological zone (state) is as shown in Table 1.

\subsection{Experimental birds and management}

During bird distribution, each of the participating smallholder poultry farmers was allocated an average of 30 prevaccinated 6-weeks-old growers of any one of the six breeds while ensuring that all the breeds were represented in each village. Each farmer, selected by a simple random sampling technique, in each of the villages received randomly selected birds of any one of the previously allocated breeds. The birds were managed under free range with basic shelter and feed supplementation provided according to each farmer's ability. Locally available supplementary feeds used by the farmers included kitchen waste, agricultural by-products and plant parts. These feeds were mostly energy-based feed resources with a similar nutrient composition across the five agroecologies (Oyewale et al., 2020). Farmers were trained during community innovation platforms on best management practices for improved health and productivity of birds. Newcastle disease vaccination and a deworming service were provided through community animal health workers (CAHWs) that were trained, supplied and supervised by veterinary officers. The cocks were raised to 20 weeks old for meat purpose, while hens were raised for eggs up to 72 weeks. At 20 weeks, the farmers were free to slaughter the cocks for meat consumption or to sell them for income, while eggs produced by the hens, over the 52-week laying period, served as a source of nutrition and income (Alabi et al., 2020). This study was approved by the International Livestock Research Institute (ILRI) Institutional Research Ethics Committee (IREC) with reference no. ILRI-IREC2015-08/1. All applicable veterinary permits for the importation, use and testing of the imported breeds, solely for research purposes, were obtained (Bamidele et al., 2019). Each farmer gave written informed consent to participate in the study.

\subsection{Research hypothesis}

\subsubsection{Null hypothesis}

There is no significant difference in growth performance, egg production and survivability of the six chicken breeds in the five agroecological zones of Nigeria 
Table 1. The number of chicken breeds distributed based on agroecological zones.

\begin{tabular}{|c|c|c|c|c|c|c|c|}
\hline \multirow{2}{*}{$\begin{array}{l}\text { Agroecological } \\
\text { zone (state) }\end{array}$} & \multicolumn{6}{|c|}{ Breed } & \multirow[t]{2}{*}{ Total } \\
\hline & Sasso & Kuroiler & $\begin{array}{l}\text { Shika- } \\
\text { Brown }\end{array}$ & $\begin{array}{r}\text { FUNAAB } \\
\text { Alpha }\end{array}$ & Noiler & Fulani & \\
\hline Imo & 2520 & 2520 & 2520 & 1440 & 2520 & 1080 & 12600 \\
\hline Kebbi & 2520 & 2520 & 2520 & 1440 & 2520 & 1080 & 12600 \\
\hline Kwara & 2520 & 2520 & 2520 & 1440 & 2520 & 1080 & 12600 \\
\hline Nasarawa & 2520 & 2520 & 2520 & 1440 & 2520 & 1080 & 12600 \\
\hline Rivers & 2520 & 2520 & 2520 & 1440 & 2310 & 1080 & 12390 \\
\hline Total & 12600 & 12600 & 12600 & 7200 & 12390 & 5400 & 62790 \\
\hline
\end{tabular}

\subsubsection{Alternative hypothesis}

The growth performance, egg production and survivability of the six chicken breeds are significantly different in the five agroecological zones under study in Nigeria.

\subsection{Data collection and statistical analyses}

Data were collected using the Open Data Kit (ODK) preloaded onto a Lenovo tablet (TAB 2 A7-30H). A field officer was assigned to each village to collect data for body weight and mortality every 4 weeks $(28 \mathrm{~d})$ from 6 to 72 weeks. In order to reduce the stress on the birds, data collection at the households started 1-2 d after bird distribution, but this inadvertently resulted in mortality due to nongenetic factors (theft, predation and stress). Farmers were pre-informed prior to field officers' visits; all birds were weighed during morning hours after overnight fasting using a suspended weighing scale with a sensitivity of $100 \mathrm{~g}$. Mortality, egg production and egg weight records were taken every 2 weeks $(14 \mathrm{~d})$ from 22 to 72 weeks. All collected data were uploaded to the ILRI data server directly from the village. All raw data are available as open-access data at http://data.ilri.org/portal/dataset/acggonfarmng (last access: 17 April 2018).

Growth rate and egg production performance data were analysed using unbalanced type-III two-way analysis of variance (ANOVA) implemented in the $\mathrm{R}$ car (version 3.0-2) package (Fox and Weisberg, 2011) to test the effect of breed, agroecologies and their interactions on the production performance of birds. Significant differences were separated using a Tukey test $(\alpha=0.05)$ for multiple comparisons through $\mathrm{R}$ least square means (version 2.30-0) (Length, 2016) and $\mathrm{R}$ multcomp (version 1.4-10) (Hothorn et al., 2008) packages.

The Cox proportional hazard regression analysis using $\mathrm{R}$ survival (version 2.42-3) (Therneau, 2015) and survminer (version 0.4.4) (Kassambara and Kosinski, 2019) packages was also used to investigate the effect of breed and agroecologies on the survival of birds. The significance of these factors was tested using Kaplan-Meier and log-rank tests. Hazard ratios were derived from Cox models. Pro- portional hazards assumed a non-significant relationship between scaled Schoenfeld residuals and time. All statistical analyses were performed in $\mathrm{R}$ version 3.5.1 ( $\mathrm{R}$ Core Team, 2018).

\section{Results}

\subsection{Growth performance of six breeds of chicken}

Significant breed variations were observed in body weight and body weight gains of male and female birds tested on-farm (Tables 2 and 3). Fulani $(303.93 \pm 10.87 \mathrm{~g})$ and Shika-Brown $(361.08 \pm 16.38 \mathrm{~g})$ had the lowest body weights at 6 weeks. The highest coefficient of variation (CV) was recorded for FUNAAB Alpha (12.97\%) and Shika-Brown $(11.11 \%)$, respectively. Breed, as a factor, significantly influenced the growth rate of male birds from 6 to 18 weeks old. Noiler males showed superiority in growth over the other five breeds from 6 to 14 weeks as shown in Table 2. However, at 18 weeks, the body weight of Noiler $(1461.28 \pm 63.15 \mathrm{~g})$, Kuroiler (1390.82 $\pm 33.82 \mathrm{~g})$ and Sasso $(1398.77 \pm 32.39 \mathrm{~g})$ were not statistically different $(p>0.05)$ from one another. Fulani had the lowest body weight $(813.75 \mathrm{~g})$ at 18 weeks.

The CV among the male birds was also highest in FUNAAB Alpha (11.05\%) and Noiler (10.59\%), while Sasso $(5.68 \%)$ and Kuroiler $(5.97 \%)$ had the lowest values at 18 weeks. The foreign-sourced breeds (Kuroiler and Sasso) had the lowest CV with similar body weights at 18 weeks compared with the other four locally sourced breeds (Noiler, Fulani, FUNAAB Alpha and Shika-Brown) that were developed in Nigeria.

In the females across the six breeds (Table 3), body weights at 6 weeks were lower than for their male counterparts. The differences in body weights of males with respect to their female counterparts at 6 weeks were as follows: Fulani (25.22 g), FUNAAB Alpha (32.19 g), Kuroiler (81.8 g), Noiler (71.31 g), Sasso (56.19 g) and Shika-Brown (36.79 g). At 18 weeks, male birds were $111.21 \mathrm{~g}$ (Fulani), $209.21 \mathrm{~g}$ (FUNAAB Alpha), 174.13g (Kuroiler), $131.06 \mathrm{~g}$ (Noiler), $148.83 \mathrm{~g}$ (Sasso) and $125.44 \mathrm{~g}$ (Shika-Brown) heavier than their female counterparts. There was no statistical differ- 
ence $(p>0.05)$ in body weights of female birds of Noiler, Kuroiler and Sasso from 6 to 18 weeks of age.

The $\mathrm{CV}$ in female body weights at 6 weeks ranking from highest to lowest is FUNAAB Alpha (21.59\%), ShikaBrown (11.38\%), Fulani (10.44\%), Kuroiler (5.16\%), Sasso $(4.49 \%)$ and Noiler $(3.77 \%)$. However, at 18 weeks old, Noiler had the highest CV (12.77\%) compared with Kuroiler $(6.18 \%)$ and Sasso $(6.93 \%)$.

\subsection{Effect of agroecological zones on the body weight of male birds}

Body weight of male birds varied significantly $(p<0.05)$ at 6 weeks in the five agroecologies where the six breeds were tested (Table 4). Body weight of male birds at 6 weeks was highest for Sasso $(858.05 \pm 23.69 \mathrm{~g})$ in Imo, Noiler in Kebbi $(737.42 \pm 16.10 \mathrm{~g})$, Kuroiler in Kwara $(848.06 \pm 24.25 \mathrm{~g})$, and for Noiler in Nasarawa $(791.52 \pm 19.51 \mathrm{~g})$ and Rivers $(591.17 \pm 24.74 \mathrm{~g})$. FUNAAB Alpha had the lowest 6-week body weight in Imo $(246.32 \pm 31.34 \mathrm{~g})$, and Shika-Brown had the lowest in Kebbi $(298.55 \pm 16.10 \mathrm{~g})$, Nasarawa (240.46 \pm $23.83 \mathrm{~g})$ and Rivers $(240.74 \pm 23.52 \mathrm{~g})$, while Fulani had the lowest body weight in Kwara $(259.06 \pm 37.31 \mathrm{~g})$. The trend in body weight increase of male birds at 10 and 14 weeks old was consistent with what was recorded at 6 weeks for all the six breeds across the five agroecologies (Table 4). The $\mathrm{CV}$ was highest for Fulani at all ages (6-18 weeks) for male birds in all the five agroecologies. The values ranged from $5.11 \%$ in Imo at 6 weeks to $7.03 \%$ in Rivers at 18 weeks.

The body weight of male birds at 18 weeks in Imo for Sasso was $1695.81 \mathrm{~g}$, while the lowest body weight was recorded in Fulani (794.83 g). In Kebbi, Kuroiler had the highest body weight and Shika-Brown the lowest. In Kwara, the highest body weight was in Kuroiler and lowest in Fulani. In both Nasarawa and Rivers, the highest body weight was in Noiler and the lowest in Fulani.

\subsection{Effect of agroecology on the body weight of female birds}

In the females (Table 5), across the agroecologies, Noiler was significantly $(p<0.05)$ heavier than all the other breeds at 6 weeks, except in Imo where Sasso $(697.31 \mathrm{~g})$ was heavier. At 18 weeks, the highest body weight observed for each breed across the agroecologies was as follows: Fulani - 952.76 g; FUNAAB Alpha - 1294.52 g (Kebbi); Noiler - 1365.39 g (Nasarawa); Kuroiler - 1464.87 g; Sasso - 1489.72 g; and Shika-Brown - 961.46 g (Imo). The breeds with the highest $(p<0.05)$ female body weight within the agroecologies were Kuroiler $(1464.87 \mathrm{~g})$ and Sasso (1489.72 g) in Imo, FUNAAB Alpha (1294.52 g), Sasso (1298.02 g), Kuroiler (1298.24 g) and Noiler (1329.47 g) in Kebbi, Kuroiler (1119.54 g) in Kwara, Sasso (1320.52 g) and Noiler (1365.39 g) in Nasarawa, and Noiler (1173.11 g) in Rivers. At 6 weeks, Kuroiler had the lowest CV at

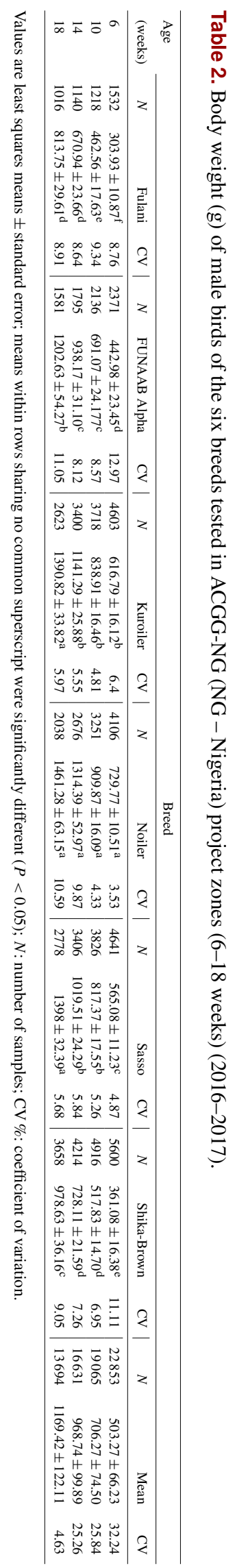

https://doi.org/10.5194/aab-63-387-2020 


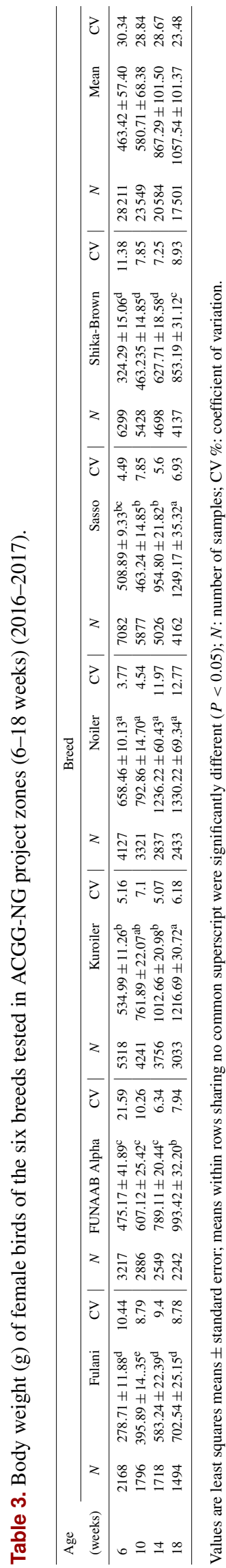

Imo $(1.57 \%)$, Kebbi $(2.63 \%)$ and Kwara $(5.8 \%)$, while Fulani $(0.98 \%)$ and Noiler $(10.75 \%)$ had the lowest CV at Nasarawa and Rivers, respectively. Also, it was observed that Shika-Brown (Kwara, $23.33 \%$; Rivers, $25.59 \%$ ), FUNAAB Alpha (Nasarawa, 11.24\%; Imo, 50.02\%) and Fulani (Kebbi, 8.63\%) had the highest CV. From 14 to 18 weeks, Fulani had the highest CV in all five agroecological zones with values that ranged between $13.78 \%$ (Kebbi) and $31.24 \%$ (Rivers) at 14 weeks and $15.50 \%$ (Kwara) and $37.79 \%$ (Rivers) at 18 weeks.

The effect of the five agroecologies on body weights of female birds of the six breeds was also studied during the laying period from 22 to 70 weeks (Table 6). Female birds showed a significant statistical difference $(p<0.05)$ in body weights in Imo, Kebbi, Kwara, Nasarawa and Rivers in the six breeds during the laying period.

The difference in body weight between the highest (Kebbi) and the lowest (Kwara) at 26 and 30 weeks was 588.48 and $586.29 \mathrm{~g}$, respectively. This pattern of weight difference was consistent for the two zones up to 48 weeks. At 54 weeks, Nasarawa had the lowest body weight $(1418.32 \pm 38.35 \mathrm{~g})$ with a difference of $523.13 \mathrm{~g}$ from the highest body weight recorded in Kebbi. The body weights of female birds were not significantly different $(p<0.05)$ in Imo, Kebbi and Rivers from 50 to 70 weeks old (Table 6), but birds in Nasarawa maintained the lowest body weight up to 70 weeks. The CV was relatively low across all the five agroecological zones for all the breeds tested. The values ranged between $4.71 \%$ in Imo at 30 weeks to $7.51 \%$ in Kwara at 70 weeks old.

\subsection{Egg production performance}

Egg production characteristics of the six breeds in the five agroecological zones are shown in Table 7. Mortality for all the breeds was lowest in Imo resulting in a higher total egg number (223379 eggs) and mean hen day production (HDEP) $(62.84 \%)$ in the 52-week laying period, compared to the other states. Although Kebbi (2972) had a higher total number of birds at 52 weeks than Imo (2465), the total egg number in 52 weeks was 192731 eggs higher in Imo than Kebbi. This difference may be attributed to the high temperature prevalent in Kebbi. Kwara had the lowest survival of birds at 72 weeks (613 birds) and the lowest mean HDEP $(23.18 \%)$ during the laying period. The total egg number in Nasarawa (81 397) was higher than Rivers (76 948); however, the mean HDEP was higher in Rivers $(57.40 \%)$ than in Nasarawa (33.50\%). It is not known whether pilferage or poor records is responsible for these anomalies. Egg production performance of the six breeds across agroecologies revealed that Shika-Brown had the highest population of birds at 72 weeks and HDEP of $45.92 \%$. FUNAAB Alpha and Kuroiler were next in mean HDEP at $45.78 \%$ and $45.68 \%$, respectively. Across the agroecologies, Fulani and Noiler had the lowest $(43.02 \mathrm{~g}$ ) and the highest $(55.31 \mathrm{~g})$ egg weights, 


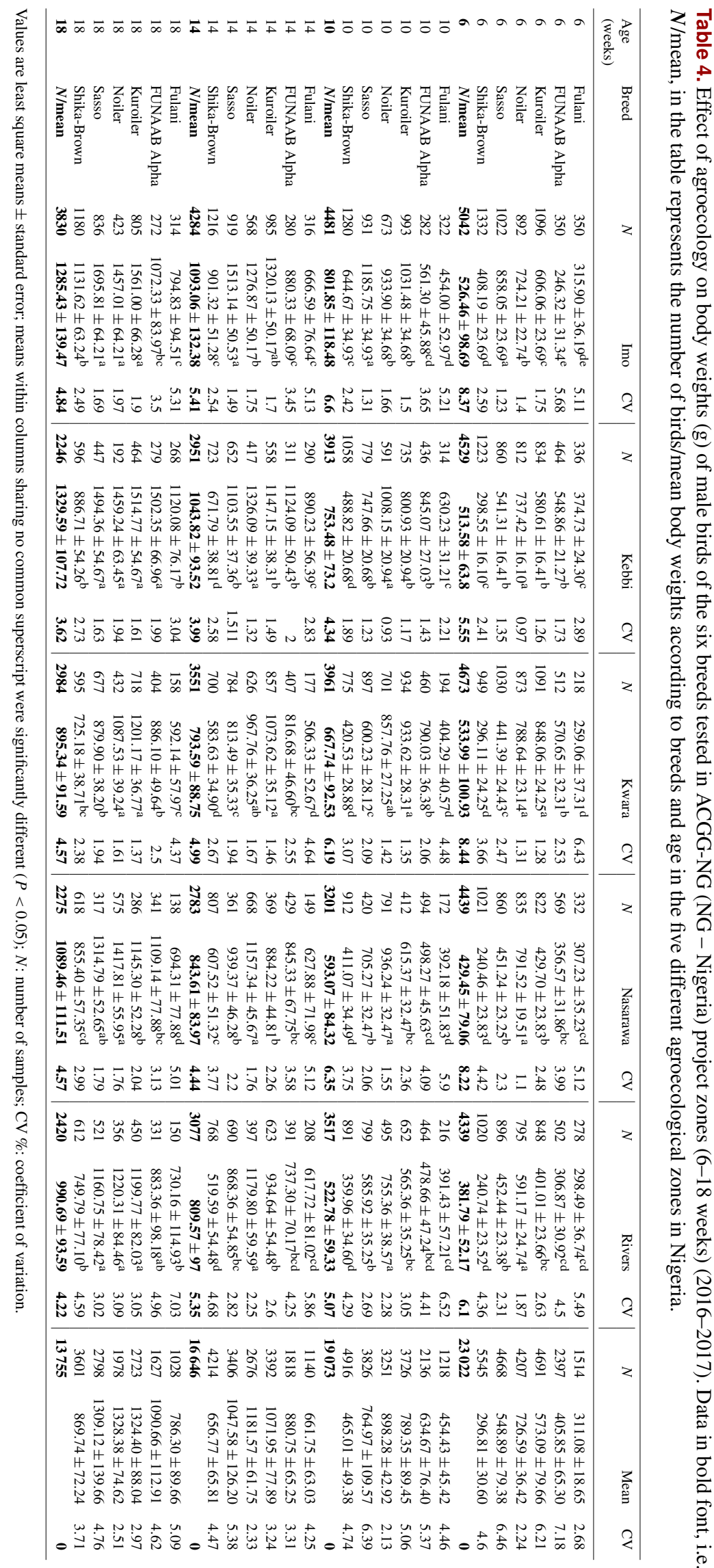




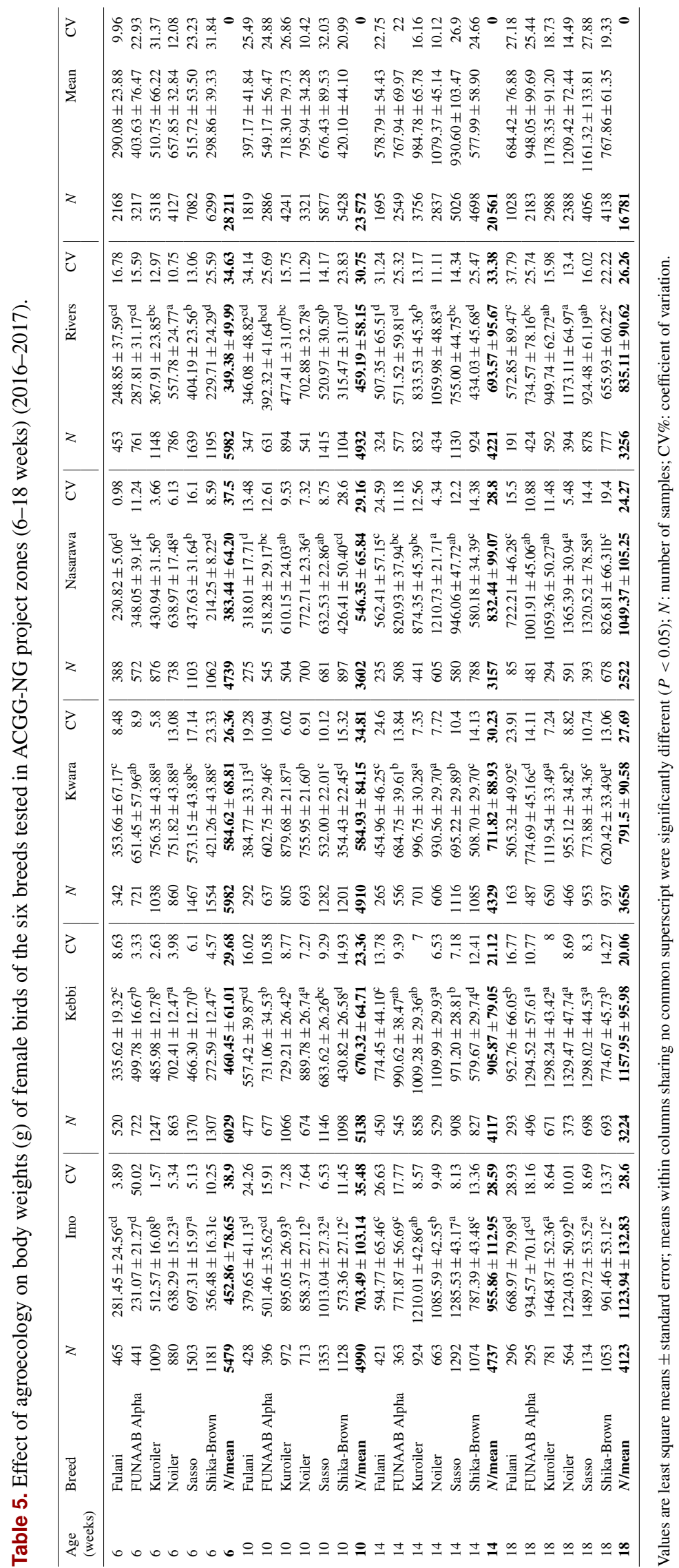




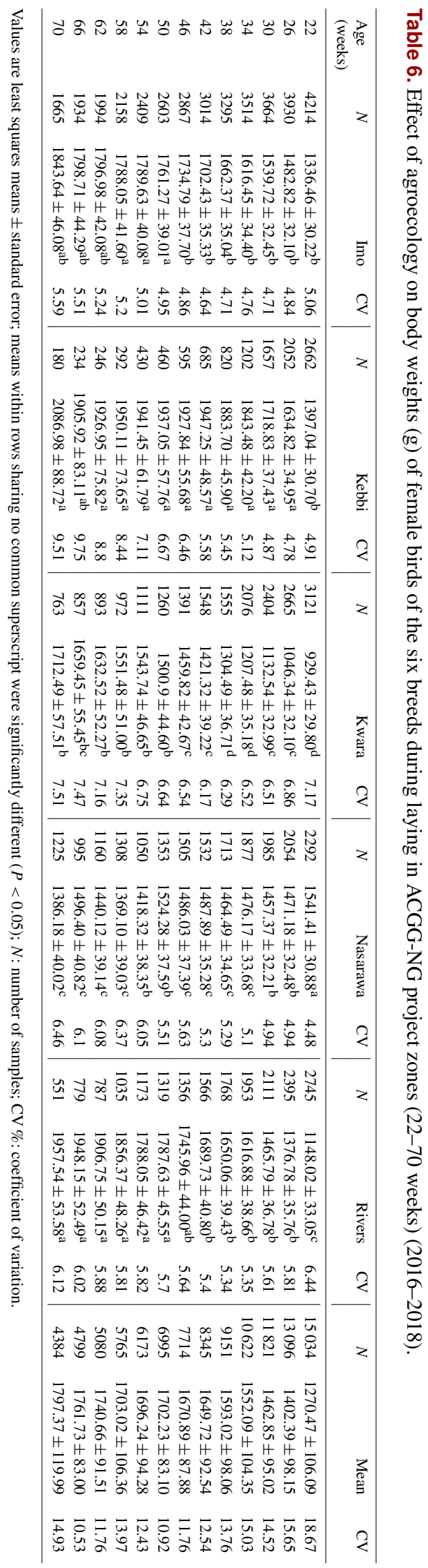

while the mean egg weight was highest in Kwara (57.49g) and lowest in Nasarawa $(47.99 \mathrm{~g})$.

\subsection{Bird mortality at growing and laying phase}

Breed and agroecologies influenced the mortality rates in male and female birds during the growing phase (Figs. 1 and 2). Nasarawa had the highest mortality rates for Fulani male $(29.8 \%)$ and female birds $(20.1 \%)$. Kwara had the highest mortality for both male and female birds of FUNAAB Alpha and Shika-Brown and only female birds of Noiler (32.4\%), Kuroiler $(29.3 \%)$ and Sasso $(25.9 \%)$. Rivers recorded the highest mortality for male Noiler $(35.1 \%)$. During the laying phase, Kwara had the highest mortality rate for all the breeds, except for Fulani, which had the highest mortality rate in Rivers (Fig. 3).

\subsection{Survival and risk factors associated with breeds of bird and agroecologies}

\subsubsection{Growing phase (6-18 weeks)}

Using age in weeks as survival time and initial and final number of birds and breeds as the covariates, the four breeds developed in Nigeria (FUNAAB Alpha, Fulani, Shika-Brown and Noiler) had higher probabilities of survival (Table 8) compared to the two foreign breeds. Kuroiler and Sasso had survival values of $0.772 \pm 0.005$ and $0.773 \pm 0.005$ and cumulative hazard ratios of $0.259 \pm 0.005$ and $0.258 \pm 0.005$, respectively from 6 to 18 weeks. The Cox proportional hazard regression model shows that Sasso had the highest risk between 6 and 10 weeks and Noiler between 10 and 18 weeks (Fig. 4), while FUNAAB Alpha maintained the lowest risk from 10 to 18 weeks (Fig. 5).

Overall survival probabilities of males and females during the growing phase (6-18 weeks) within agroecologies are shown in Table 9. Imo had the highest survival probability $(0.849 \pm 0.004)$ for all birds, which was followed closely by Nasarawa and Kebbi. Overall survival probability for all breeds was slightly higher in Rivers $(0.754 \pm 0.006)$ than Kwara $(0.715 \pm 0.006)$. Kaplan-Meier survival curves show fewer probabilities of survival in Kwara and Rivers from 6 to 18 weeks (Fig. 6) and a cumulative force of mortality of $0.336 \pm 0.006$ (Table 8). Significant cumulative hazards were recorded for the overall performance of birds (Fig. 7) during the growing stage (6-18 weeks). A Cox regression model revealed that Rivers had more birds at risk of death from 6 to 14 weeks, while between 14 and 18 weeks old Kwara had more birds at risk of death (Fig. 7).

\subsubsection{Laying phase (20-72 weeks)}

Survival probability was influenced significantly by breed of birds during the laying period (Table 10). Noiler had the highest survivability (0.822) and the lowest number of birds at risk of death (0.196), while Kuroiler was the lowest in 
Table 7. Total egg production per breed and by location in ACGG Nigeria project zones (2016-2018).

\begin{tabular}{|c|c|c|c|c|c|c|}
\hline State & Breed & $\begin{array}{l}\text { No. birds at } \\
22 \text { weeks }\end{array}$ & $\begin{array}{l}\text { No. birds at } \\
72 \text { weeks }\end{array}$ & $\begin{array}{l}\text { Total no. } \\
\text { of eggs in } \\
52 \text { weeks }\end{array}$ & $\begin{array}{r}\text { Average egg } \\
\text { weight }(\mathrm{g})\end{array}$ & $\operatorname{HDEP}(\%)$ \\
\hline \multirow[t]{7}{*}{ Imo } & Fulani & 399 & 195 & 14046 & 38.57 & 62.04 \\
\hline & FUNAAB Alpha & 331 & 186 & 14228 & 49.29 & 60.81 \\
\hline & Kuroiler & 822 & 469 & 37131 & 56.09 & 65.46 \\
\hline & Noiler & 607 & 364 & 34978 & 55.17 & 62.59 \\
\hline & Sasso & 1210 & 575 & 33852 & 54.99 & 61.26 \\
\hline & Shika-Brown & 1057 & 676 & 89144 & 53.50 & 64.87 \\
\hline & Total & 4426 & 2465 & 223379 & 51.27 & 62.84 \\
\hline \multirow[t]{7}{*}{ Kebbi } & Fulani & 433 & 296 & 2857 & 41.43 & 40.85 \\
\hline & FUNAAB Alpha & 542 & 354 & 5222 & 56.07 & 46.02 \\
\hline & Kuroiler & 900 & 616 & 4110 & 55.81 & 48.45 \\
\hline & Noiler & 526 & 394 & 5393 & 58.36 & 32.51 \\
\hline & Sasso & 945 & 646 & 2681 & 54.41 & 43.83 \\
\hline & Shika-Brown & 971 & 666 & 10385 & 53.78 & 36.49 \\
\hline & Total & 4317 & 2972 & 30648 & 53.31 & 41.36 \\
\hline \multirow[t]{7}{*}{ Kwara } & Fulani & 253 & 84 & 2134 & 46.87 & 17.63 \\
\hline & FUNAAB Alpha & 501 & 34 & 1791 & 56.54 & 20.00 \\
\hline & Kuroiler & 638 & 24 & 4248 & 63.94 & 24.69 \\
\hline & Noiler & 482 & 163 & 8382 & 61.19 & 32.74 \\
\hline & Sasso & 960 & 165 & 3839 & 61.13 & 19.76 \\
\hline & Shika-Brown & 978 & 143 & 6001 & 55.25 & 24.25 \\
\hline & Total & 3812 & 613 & 26395 & 57.49 & 23.18 \\
\hline \multirow[t]{7}{*}{ Nasarawa } & Fulani & 253 & 142 & 4829 & 44.43 & 33.66 \\
\hline & FUNAAB Alpha & 539 & 317 & 12431 & 48.36 & 33.16 \\
\hline & Kuroiler & 512 & 248 & 9051 & 49.06 & 35.35 \\
\hline & Noiler & 872 & 765 & 21423 & 48.53 & 27.37 \\
\hline & Sasso & 685 & 316 & 9312 & 50.68 & 35.97 \\
\hline & Shika-Brown & 840 & 530 & 24351 & 46.95 & 35.47 \\
\hline & Total & 3701 & 2318 & 81397 & 47.99 & 33.50 \\
\hline \multirow[t]{7}{*}{ Rivers } & Fulani & 363 & 98 & 9655 & 43.78 & 55.91 \\
\hline & FUNAAB Alpha & 551 & 187 & 15082 & 49.68 & 68.89 \\
\hline & Kuroiler & 663 & 199 & 10794 & 52.05 & 54.44 \\
\hline & Noiler & 308 & 91 & 14238 & 53.31 & 52.32 \\
\hline & Sasso & 1009 & 357 & 6866 & 50.89 & 44.31 \\
\hline & Shika-Brown & 871 & 463 & 20313 & 49.35 & 68.53 \\
\hline & Total & 3765 & 1395 & 76948 & 49.84 & 57.40 \\
\hline \multirow{7}{*}{$\begin{array}{l}\text { Across agro- } \\
\text { ecologies }\end{array}$} & Fulani & 1701 & 815 & 33521 & 43.02 & 42.02 \\
\hline & FUNAAB Alpha & 2464 & 1078 & 48754 & 51.98 & 45.78 \\
\hline & Kuroiler & 3535 & 1556 & 65334 & 55.39 & 45.68 \\
\hline & Noiler & 2795 & 1777 & 84414 & 55.31 & 41.51 \\
\hline & Sasso & 4809 & 2059 & 56550 & 54.42 & 41.03 \\
\hline & Shika-Brown & 4717 & 2478 & 150194 & 51.77 & 45.92 \\
\hline & Total & 20021 & 9763 & 438767 & 51.98 & 43.66 \\
\hline
\end{tabular}

HDEP: mean hen day egg production. 


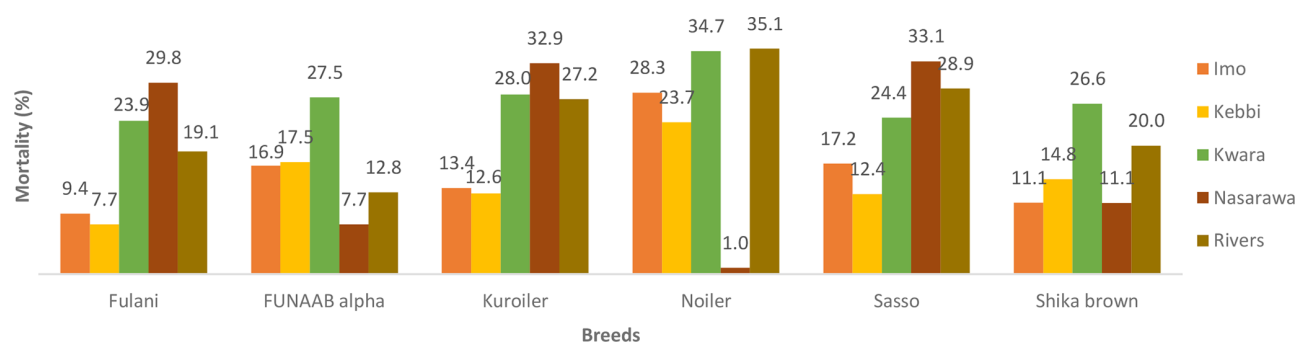

Figure 1. Actual mortality of male birds during growing phase in ACGG project zones (6-18 weeks) (2016-2017).

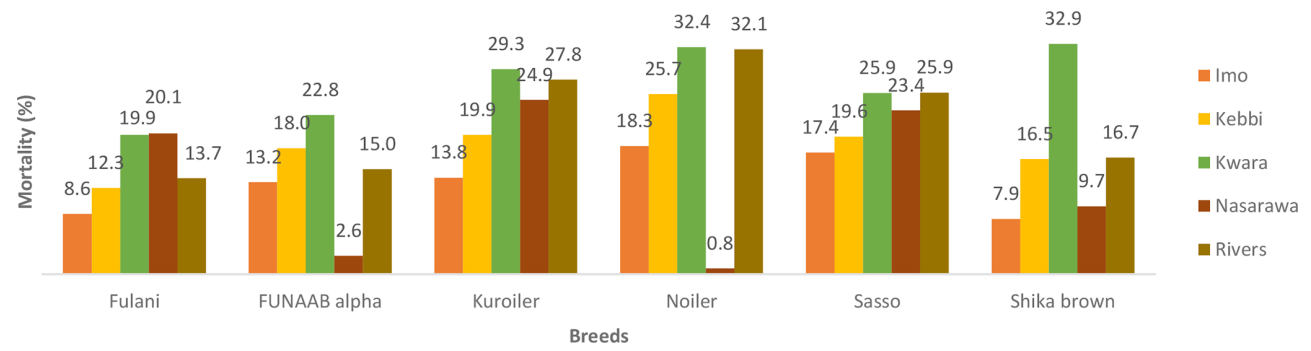

Figure 2. Actual mortality of female birds during growing phase in ACGG project zones (6-18 weeks) (2016-2017).

survival ability (0.699), having more birds at risk of death. Survival curves also showed that Noiler had more female birds during laying than other breeds (Fig. 8), and the cumulative hazard (Fig. 9) for birds at risk of death was highest in Kuroiler laying hens.

Birds in Nasarawa had the highest survivability potential of $91.9 \%$ and the lowest risk of death (Table 11), while birds in Kwara had the lowest survivability $(46.1 \%)$ and the highest risk of death (0.775). Survival and cumulative hazard for agroecologies are shown in Figs. 10 and 11.

\subsection{Breed $\times$ environment interaction on survival and risk factors of birds}

\subsubsection{Growing phase (6-18 weeks)}

Breed by environment interaction effect on the growth of birds revealed that two breeds in Imo that survived best were Shika-Brown (90.4\%) and Fulani (90.8\%) (Table 12). In Kebbi, Fulani $(89.6 \%)$ and Shika-Brown $(84.3 \%)$ and in Kwara Fulani $(78.9 \%)$ and FUNAAB Alpha $(75.2 \%)$ had the highest survival probabilities. In Nasarawa, the highest survival probabilities were recorded for Noiler $(99.2 \%)$ and FUNAAB Alpha (95\%); and in Rivers survival probabilities were highest for FUNAAB Alpha $(85.9 \%)$ and Fulani $(83.9 \%)$. Survival probabilities of growing birds according to age and breeds are displayed in Fig. 12. Breeds with the highest risk of death were Fulani (at 14-18 weeks) in Nasarawa, Noiler (at 10-18 weeks) in Rivers and ShikaBrown (at 10-18 weeks) in Kwara (Fig. 13). Agroecology by breed interaction varied with respect to probabilities of survival and cumulative hazards across the five zones at different ages of the birds (Figs. 14 and 15). Noiler had its highest risk of death in Imo, Kebbi and Rivers (Fig. 15).

\subsubsection{Laying phase (20-72 weeks)}

Breed $\times$ environment interaction on survivability of birds was significant $(p<0.0001)$ during the laying phase (Table 13). For the relative survival probabilities across agroecologies and breeds, Noiler (0.84) and Shika-Brown (0.79) ranked first and second, while the lowest-ranked genotype was Sasso (0.69) in Imo. Fulani (0.92) and Noiler (0.89) were in first and second position, while Shika-Brown (0.85) was ranked lowest in Kebbi. Fulani (0.55) and Noiler (0.55) were ranked first and second while Kuroiler (0.23) was the lowest in Kwara. In Nasarawa, the survivability potential was 0.94 (Noiler and FUNAAB Alpha), while in Rivers, Shika-Brown (0.80) and Fulani (0.62) had the highest and lowest survivability potential, respectively (Table 13). Overall, Kwara had the lowest survivability (Fig. 16), while Nasarawa had the highest survivability for all the breeds during laying. Kuroiler (1.48) had the highest cumulative hazard for probabilities of death in Kwara (Fig. 17). The agroecological zone effect on survival probability revealed that Nasarawa had the highest probabilities for all the breeds (Fig. 18). Kebbi ranked next in survival probability, followed by Imo; Rivers and Kwara were lowest in ranking. The cumulative hazard risk was the lowest for Fulani across all the five agroecologies (Fig. 19). The cumulative risk of death was highest in Kwara for all the six breeds, while Nasarawa had the lowest risk. 


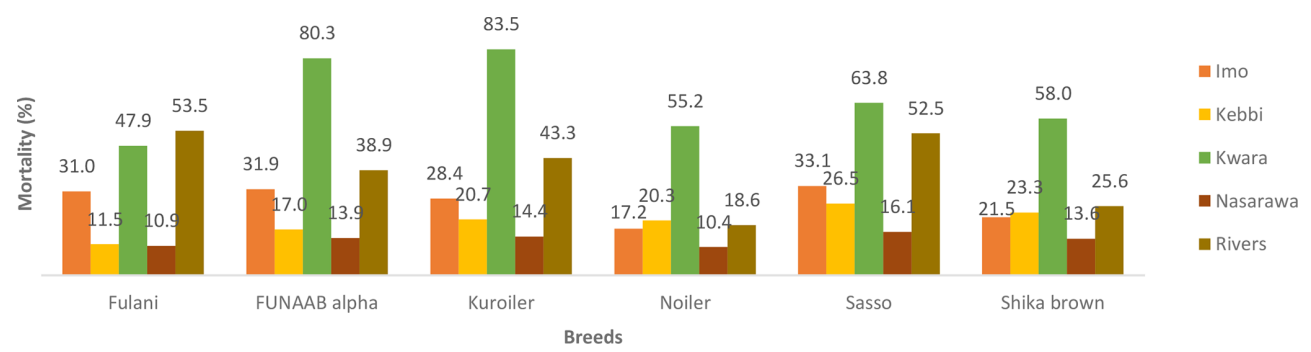

Figure 3. Actual mortality of female birds during laying phase in ACGG project zones (20-72 weeks) (2016-2018).

Table 8. Effect of breed on overall on-farm survival performance of birds (male and female) during growing phase in ACGG Nigeria project zones (6-18 weeks) (2016-2017).

\begin{tabular}{lrrrrr}
\hline Breeds & IN & FN & Survival probability \pm SE & Cumulative hazard \pm SE & Log rank $(P$ value $)$ \\
\hline Fulani & 3682 & 3229 & $0.844 \pm 0.007$ & $0.17 \pm 0.007$ & $2.27 \times 10^{-69}$ \\
FUNAAB Alpha & 5614 & 4968 & $0.845 \pm 0.006$ & $0.168 \pm 0.006$ & \\
Kuroiler & 10009 & 8221 & $0.772 \pm 0.005$ & $0.259 \pm 0.005$ & \\
Noiler & 8329 & 6775 & $0.765 \pm 0.006$ & $0.267 \pm 0.006$ & \\
Sasso & 11750 & 9628 & $0.773 \pm 0.005$ & $0.258 \pm 0.005$ & \\
Shika-Brown & 11844 & 10265 & $0.827 \pm 0.004$ & $0.19 \pm 0.004$ & \\
\hline
\end{tabular}

IN and FN: initial and final number of birds; SE: standard error; log rank: test of homogeneity for differences in survival.

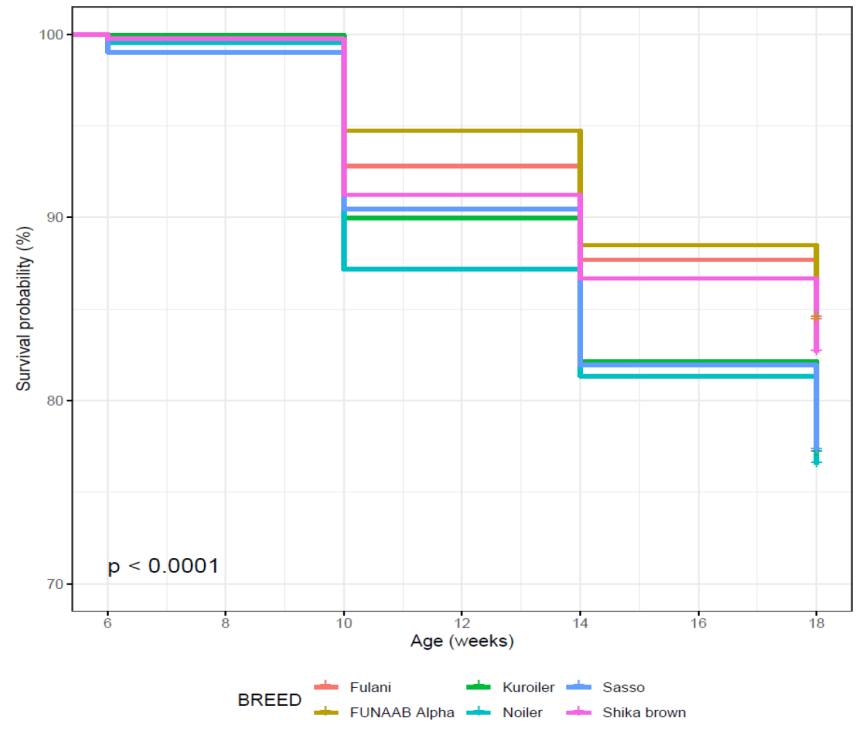

Figure 4. Effect of breed on overall on-farm survival performance of birds (male and female) during growing phase in ACGG Nigeria project zones (6-18 weeks) (2016-2017).

\section{Discussion}

\subsection{Growth performance of six breeds of chicken}

An on-farm study provides a more realistic performance of tested birds under farmers' management practices (Sorensen, 2010). Significant breed variations in growth performance of male and female birds of the six breeds tested on-farm in five

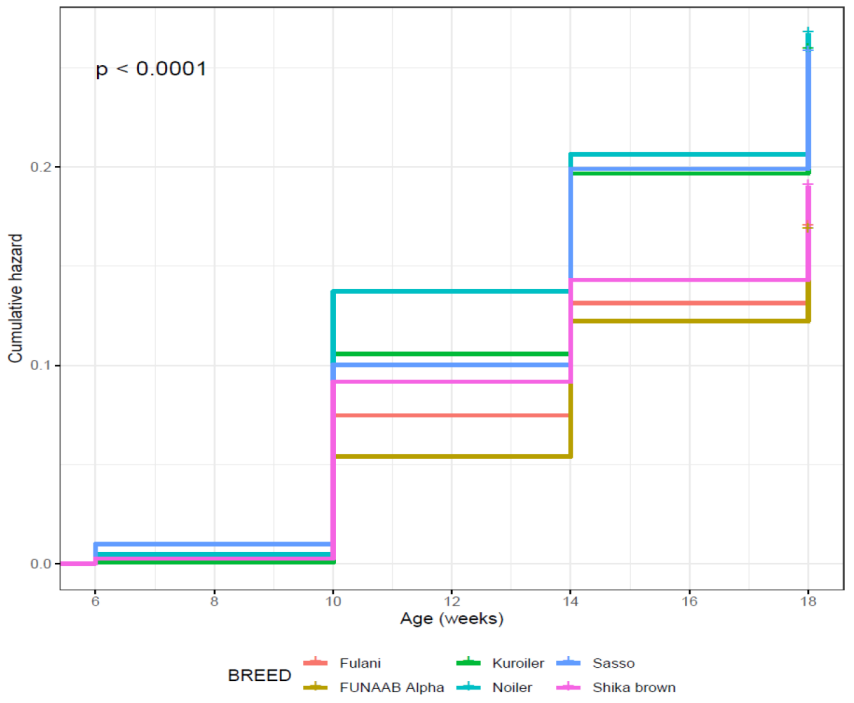

Figure 5. Effect of breed on overall on-farm cumulative hazard of birds (male and female) during growing phase in ACGG Nigeria project zones (6-18 weeks) (2016-2017).

agroecological zones were revealed. Male birds had a fast growth rate from 6 to 10 weeks and a slower growth rate from 14 to 18 weeks old. Noiler showed an unusually higher body weight gain between 10 and 14 weeks, which was different from the other breeds. Breed differences in productivity and survivability of Vanaraja, Rhode Island Red (RIR) and Deshi birds in the Gorkhaland Territorial Administration (GTA) a semi-autonomous administrative body for the Darjeeling 
Table 9. Effect of agroecology on overall on-farm survival performance of birds (male and female) during growing phase in ACGG Nigeria project zones (6-18 weeks) (2016-2017).

\begin{tabular}{lrrrrr}
\hline State & IN & FN & Survival probability \pm SE & Cumulative hazard \pm SE & Log rank $(P$ value $)$ \\
\hline Imo & 10351 & 9183 & $0.849 \pm 0.004$ & $0.164 \pm 0.004$ & $1.92 \times 10^{-201}$ \\
Kebbi & 10438 & 9065 & $0.824 \pm 0.005$ & $0.194 \pm 0.005$ & \\
Kwara & 10550 & 8253 & $0.715 \pm 0.006$ & $0.336 \pm 0.006$ & \\
Nasarawa & 9747 & 8399 & $0.846 \pm 0.004$ & $0.167 \pm 0.004$ & \\
Rivers & 10142 & 8186 & $0.754 \pm 0.006$ & $0.283 \pm 0.006$ & \\
\hline
\end{tabular}

IN and FN: initial and final number of birds; SE: standard error; log rank: test of homogeneity for differences in survival.

Table 10. Effect of breed on survival performance of female birds raised on-farm during laying phase in ACGG Nigeria project zones (20-72 weeks) (2016-2018).

\begin{tabular}{lrrrrr}
\hline Breeds & IN & FN & Survival probability \pm SE & Cumulative hazard \pm SE & Log rank $(P$ value $)$ \\
\hline Fulani & 1701 & 1279 & $0.75 \pm 0.014$ & $0.287 \pm 0.014$ & $3.87 \times 10^{-35}$ \\
FUNAAB Alpha & 2464 & 1775 & $0.716 \pm 0.013$ & $0.335 \pm 0.013$ & \\
Kuroiler & 3535 & 1906 & $0.699 \pm 0.011$ & $0.358 \pm 0.011$ & \\
Noiler & 2795 & 2311 & $0.822 \pm 0.009$ & $0.196 \pm 0.009$ & \\
Sasso & 4809 & 3508 & $0.725 \pm 0.009$ & $0.321 \pm 0.009$ & \\
Shika-Brown & 4717 & 3693 & $0.773 \pm 0.008$ & $0.258 \pm 0.008$ & \\
\hline
\end{tabular}

IN and FN: initial and final number of birds; SE: standard error; log rank: test of homogeneity for differences in survival.

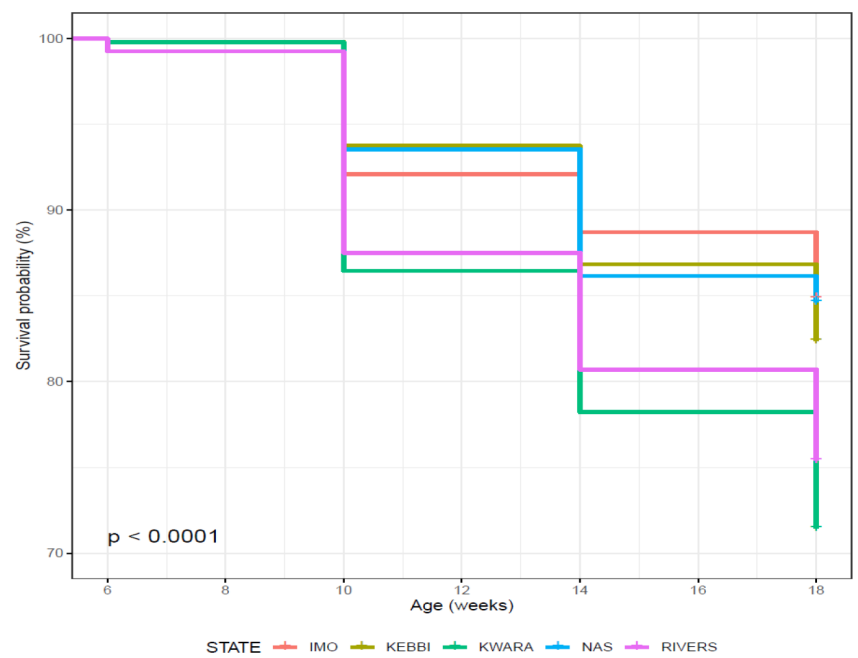

Figure 6. Effect of agroecology on overall on-farm survival performance of birds (male and female) during growing phase in ACGG Nigeria project zones (6-18 weeks) (2016-2017).

Hills in West Bengal, India - have been documented by Roy et al. (2017). The performance of Vanaraja, a dual-purpose breed, was better than RIR in terms of body weight gain from 4 to 20 weeks of age with reduced mortality. Noiler, also a dual-purpose breed developed in Nigeria, showed better performance in body weight gain than Kuroiler and Sasso, which are also dual-purpose and tropically adapted breeds but not indigenous to Nigeria.

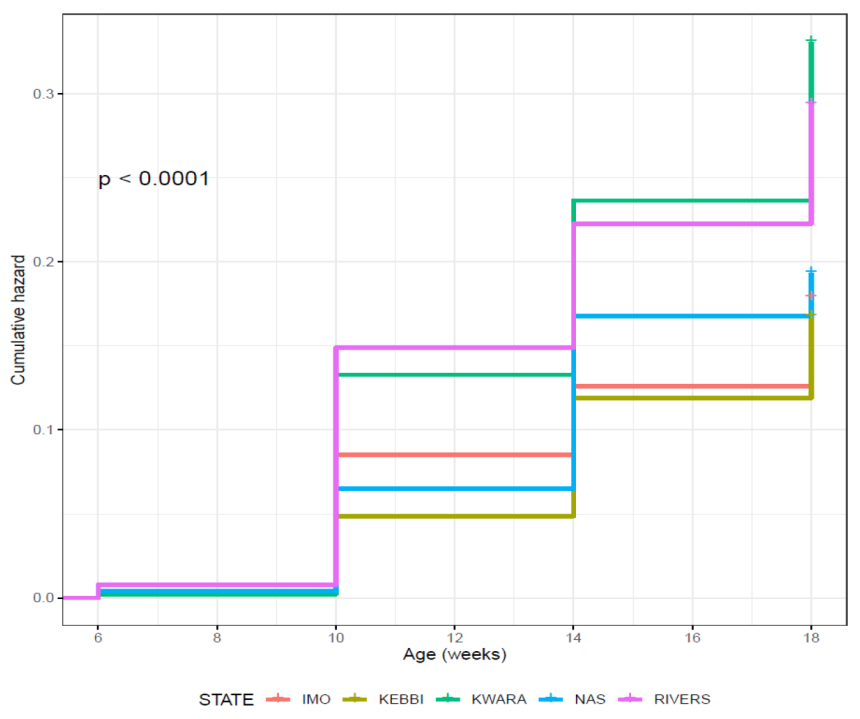

Figure 7. Effect of agroecologies on overall on-farm cumulative hazard of birds (male and female) during growing phase in ACGG Nigeria project zones (6-18 weeks) (2016-2017).

Compared with the average male body weight $(680 \mathrm{~g})$ of local chickens at 18 weeks (Nwosu, 1979; Nwosu and Asuquo, 1985; Olori and Sonaiya, 1992; Adedokun and Sonaiya, 2002; Ajayi, 2010) the breeds were higher by $119.7 \%$ (Fulani), $143.9 \%$ (Shika-Brown), $176.9 \%$ (FUNAAB Alpha), $204.5 \%$ (Kuroiler), $205.6 \%$ (Sasso) and $214.9 \%$ (Noiler). This shows the clustering of the breeds into 
Table 11. Effect of agroecologies on survival performance of female birds raised on-farm in ACGG Nigeria project zones (22-70 weeks) (2016-2018).

\begin{tabular}{lrrrrr}
\hline State & IN & FN & Survival probability \pm SE & Cumulative hazard \pm SE & Log rank $(P$ value $)$ \\
\hline Imo & 4426 & 2715 & $0.744 \pm 0.009$ & $0.296 \pm 0.009$ & 0 \\
Kebbi & 4317 & 3778 & $0.874 \pm 0.006$ & $0.135 \pm 0.006$ & \\
Kwara & 3812 & 1839 & $0.461 \pm 0.018$ & $0.775 \pm 0.018$ & \\
Nasarawa & 3701 & 3408 & $0.919 \pm 0.005$ & $0.085 \pm 0.005$ & \\
Rivers & 3765 & 2732 & $0.724 \pm 0.01$ & $0.323 \pm 0.01$ & \\
\hline
\end{tabular}

IN and FN: initial and final number of birds SE: standard error; log rank: test of homogeneity for differences in survival.

Table 12. Breed by environment interaction on survivability of birds (male and female) during growing in ACGG Nigeria project zones (6-18 weeks) (2016-2017).

\begin{tabular}{|c|c|c|c|c|c|c|}
\hline State & Breeds & IN & $\mathrm{FN}$ & Survival probability \pm SE & Cumulative hazard $\pm \mathrm{SE}$ & Log rank ( $p$ value) \\
\hline \multirow[t]{6}{*}{ Imo } & Fulani & 792 & 745 & $0.908 \pm 0.011$ & $0.097 \pm 0.011$ & $7.10 \times 10^{-269}$ \\
\hline & FUNAAB alpha & 739 & 625 & $0.842 \pm 0.016$ & $0.172 \pm 0.016$ & \\
\hline & Kuroiler & 2100 & 1924 & $0.864 \pm 0.009$ & $0.146 \pm 0.009$ & \\
\hline & Noiler & 1680 & 1371 & $0.754 \pm 0.014$ & $0.282 \pm 0.014$ & \\
\hline & Sasso & 2520 & 2187 & $0.827 \pm 0.009$ & $0.19 \pm 0.009$ & \\
\hline & Shika-Brown & 2520 & 2331 & $0.904 \pm 0.006$ & $0.101 \pm 0.006$ & \\
\hline \multirow[t]{6}{*}{ Kebbi } & Fulani & 865 & 805 & $0.896 \pm 0.012$ & $0.11 \pm 0.012$ & \\
\hline & FUNAAB alpha & 1195 & 1032 & $0.823 \pm 0.013$ & $0.194 \pm 0.013$ & \\
\hline & Kuroiler & 2064 & 1823 & $0.829 \pm 0.01$ & $0.188 \pm 0.01$ & \\
\hline & Noiler & 1664 & 1327 & $0.751 \pm 0.014$ & $0.286 \pm 0.014$ & \\
\hline & Sasso & 2130 & 1878 & $0.823 \pm 0.01$ & $0.194 \pm 0.01$ & \\
\hline & Shika-Brown & 2520 & 2200 & $0.843 \pm 0.009$ & $0.171 \pm 0.009$ & \\
\hline \multirow[t]{6}{*}{ Kwara } & Fulani & 570 & 475 & $0.789 \pm 0.022$ & $0.236 \pm 0.022$ & \\
\hline & FUNAAB alpha & 1230 & 1028 & $0.752 \pm 0.016$ & $0.285 \pm 0.016$ & \\
\hline & Kuroiler & 2100 & 1592 & $0.71 \pm 0.014$ & $0.342 \pm 0.014$ & \\
\hline & Noiler & 1659 & 1242 & $0.649 \pm 0.018$ & $0.432 \pm 0.018$ & \\
\hline & Sasso & 2498 & 2016 & $0.747 \pm 0.012$ & $0.291 \pm 0.012$ & \\
\hline & Shika-Brown & 2493 & 1900 & $0.694 \pm 0.013$ & $0.365 \pm 0.013$ & \\
\hline \multirow[t]{6}{*}{ Nasarawa } & Fulani & 740 & 574 & $0.761 \pm 0.021$ & $0.273 \pm 0.021$ & \\
\hline & FUNAAB alpha & 1188 & 1155 & $0.95 \pm 0.007$ & $0.051 \pm 0.007$ & \\
\hline & Kuroiler & 1791 & 1330 & $0.728 \pm 0.014$ & $0.318 \pm 0.014$ & \\
\hline & Noiler & 1820 & 1809 & $0.992 \pm 0.002$ & $0.008 \pm 0.002$ & \\
\hline & Sasso & 2087 & 1580 & $0.74 \pm 0.013$ & $0.301 \pm 0.013$ & \\
\hline & Shika-Brown & 2121 & 1951 & $0.898 \pm 0.007$ & $0.107 \pm 0.007$ & \\
\hline \multirow[t]{6}{*}{ Rivers } & Fulani & 715 & 630 & $0.839 \pm 0.016$ & $0.175 \pm 0.016$ & \\
\hline & FUNAAB alpha & 1262 & 1128 & $0.859 \pm 0.011$ & $0.152 \pm 0.011$ & \\
\hline & Kuroiler & 1954 & 1552 & $0.719 \pm 0.014$ & $0.331 \pm 0.014$ & \\
\hline & Noiler & 1506 & 1026 & $0.647 \pm 0.019$ & $0.435 \pm 0.019$ & \\
\hline & Sasso & 2515 & 1967 & $0.728 \pm 0.012$ & $0.317 \pm 0.012$ & \\
\hline & Shika-Brown & 2190 & 1883 & $0.8 \pm 0.011$ & $0.223 \pm 0.011$ & \\
\hline
\end{tabular}

IN and FN: initial and final number of birds SE: standard error; log rank: test of homogeneity for differences in survival. 
Table 13. Breed by environment interaction on survivability of female birds raised on-farm in ACGG Nigeria project zones (22-70 weeks) (2016-2018).

\begin{tabular}{|c|c|c|c|c|c|c|}
\hline State & Breeds & IN & $\mathrm{FN}$ & Survival probability $\pm \mathrm{SE}$ & Cumulative hazard $\pm \mathrm{SE}$ & Log rank ( $p$ value) \\
\hline \multirow[t]{6}{*}{ Imo } & Fulani & 399 & 279 & $0.699 \pm 0.033$ & $0.358 \pm 0.033$ & 0 \\
\hline & FUNAAB alpha & 331 & 238 & $0.716 \pm 0.035$ & $0.334 \pm 0.035$ & \\
\hline & Kuroiler & 822 & 606 & $0.735 \pm 0.021$ & $0.308 \pm 0.021$ & \\
\hline & Noiler & 607 & 510 & $0.84 \pm 0.018$ & $0.174 \pm 0.018$ & \\
\hline & Sasso & 1210 & 845 & $0.69 \pm 0.019$ & $0.371 \pm 0.019$ & \\
\hline & Shika-Brown & 1057 & 843 & $0.786 \pm 0.016$ & $0.241 \pm 0.016$ & \\
\hline \multirow[t]{6}{*}{ Kebbi } & Fulani & 433 & 398 & $0.915 \pm 0.015$ & $0.089 \pm 0.015$ & \\
\hline & FUNAAB alpha & 542 & 463 & $0.854 \pm 0.018$ & $0.158 \pm 0.018$ & \\
\hline & Kuroiler & 900 & 794 & $0.882 \pm 0.012$ & $0.125 \pm 0.012$ & \\
\hline & Noiler & 526 & 469 & $0.892 \pm 0.015$ & $0.115 \pm 0.015$ & \\
\hline & Sasso & 945 & 825 & $0.873 \pm 0.012$ & $0.136 \pm 0.012$ & \\
\hline & Shika-Brown & 971 & 829 & $0.85 \pm 0.014$ & $0.163 \pm 0.014$ & \\
\hline \multirow[t]{6}{*}{ Kwara } & Fulani & 253 & 140 & $0.553 \pm 0.056$ & $0.592 \pm 0.056$ & \\
\hline & FUNAAB alpha & 501 & 201 & $0.381 \pm 0.057$ & $0.964 \pm 0.057$ & \\
\hline & Kuroiler & 638 & 171 & $0.229 \pm 0.073$ & $1.475 \pm 0.073$ & \\
\hline & Noiler & 482 & 277 & $0.548 \pm 0.041$ & $0.602 \pm 0.041$ & \\
\hline & Sasso & 960 & 493 & $0.506 \pm 0.032$ & $0.681 \pm 0.032$ & \\
\hline & Shika-Brown & 978 & 557 & $0.542 \pm 0.029$ & $0.613 \pm 0.029$ & \\
\hline \multirow[t]{6}{*}{ Nasarawa } & Fulani & 253 & 235 & $0.929 \pm 0.017$ & $0.074 \pm 0.017$ & \\
\hline & FUNAAB alpha & 539 & 484 & $0.896 \pm 0.015$ & $0.11 \pm 0.015$ & \\
\hline & Kuroiler & 512 & 478 & $0.926 \pm 0.013$ & $0.077 \pm 0.013$ & \\
\hline & Noiler & 872 & 815 & $0.935 \pm 0.009$ & $0.068 \pm 0.009$ & \\
\hline & Sasso & 685 & 633 & $0.924 \pm 0.011$ & $0.079 \pm 0.011$ & \\
\hline & Shika-Brown & 840 & 763 & $0.905 \pm 0.011$ & $0.1 \pm 0.011$ & \\
\hline \multirow[t]{6}{*}{ Rivers } & Fulani & 363 & 227 & $0.623 \pm 0.041$ & $0.474 \pm 0.041$ & \\
\hline & FUNAAB alpha & 551 & 389 & $0.706 \pm 0.027$ & $0.348 \pm 0.027$ & \\
\hline & Kuroiler & 663 & 463 & $0.697 \pm 0.026$ & $0.361 \pm 0.026$ & \\
\hline & Noiler & 308 & 240 & $0.779 \pm 0.03$ & $0.249 \pm 0.03$ & \\
\hline & Sasso & 1009 & 712 & $0.703 \pm 0.02$ & $0.353 \pm 0.02$ & \\
\hline & Shika-Brown & 871 & 701 & $0.803 \pm 0.017$ & $0.22 \pm 0.017$ & \\
\hline
\end{tabular}

IN and FN: initial and final number of birds; SE: standard error; log rank: test of homogeneity for differences in survival.

two groups of faster-growing (Kuroiler, Sasso and Noiler), and slower-growing breeds (Fulani, FUNAAB Alpha and Shika-Brown).

\subsection{Effect of agroecologies on growth performance of birds}

On-farm trials revealed that agroecologies had a significant effect on the live body weight of the six breeds studied. Hassan et al. (2018) earlier reported that there was a breed $\times$ agroecology interaction effect on the body weight of these six breeds at the brooding stage (0-6 weeks). The difference in the environmental factors across the five agroecologies was adjusted by the CV for each variable. Growth performance of female birds during the laying period was affected by agroecology. Laying birds have been reported to differ in their adaptability to husbandry systems (Yakubu et al., 2007) and climatic factors (Garcês et al., 2001). An in- crease in body weight during the laying period as was observed in Kebbi (Sudan savanna) was at variance with the reports of Garcês et al. (2001) that elevated temperatures reduced the body weight of laying birds.

\section{3 $\quad$ Breed $\times$ agroecology interaction effect on egg production}

A higher total number of birds at 72 weeks in Kebbi (Sudan savanna/northern Guinea savanna) did not correspond to higher HDEP; rather, birds in Imo (lowland rainforest and freshwater swamp) had higher HDEP than those in Kebbi. Hot dry agroecologies have been reported to reduce egg number (Garcês et al., 2001) and increase the probability of death (Shittu et al., 2014) in laying birds. High HDEP in Imo $(62.84 \%)$ and Rivers $(57.40 \%)$, lowland rainforest and freshwater swamp, respectively, may be attributed to lower ambient temperatures in the two 


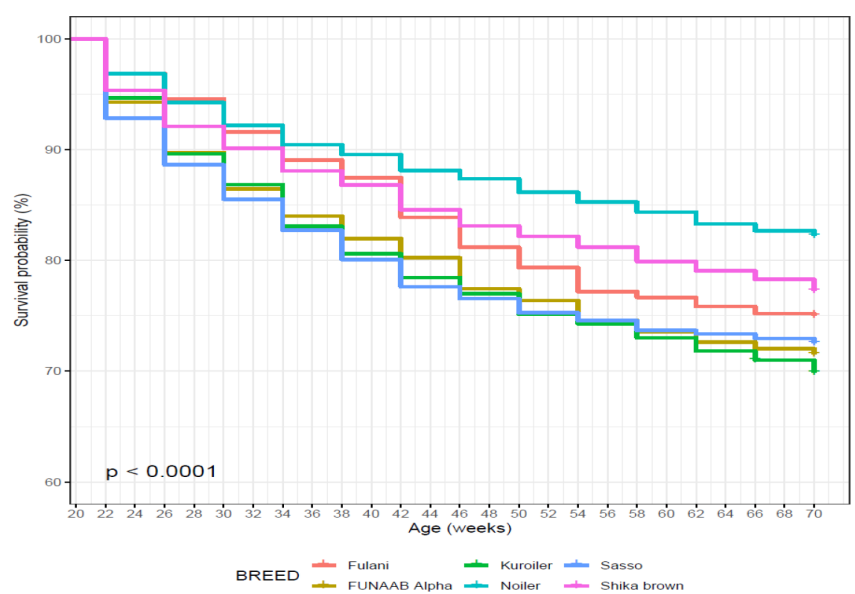

Figure 8. Effect of breed on survival performance of female birds raised on-farm in ACGG Nigeria project zones (20-72 weeks) (2016-2018).

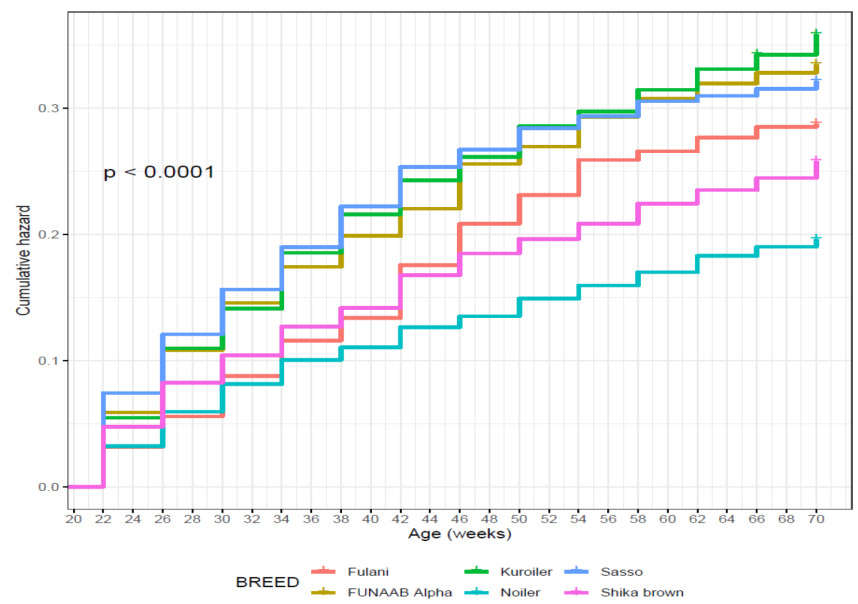

Figure 9. Effect of breed on cumulative hazard of female birds raised on-farm during laying phase in ACGG Nigeria project zones (20-72 weeks) (2016-2018).

zones compared with higher ambient temperatures in Kwara $(23.18 \%)$, Nasarawa $(33.50 \%)$ and Kebbi $(41.36 \%)$. The HDEP observed in this study was higher (Imo and Rivers) and lower (Kwara, Nasarawa, Kebbi) than the $44.7 \%$ (rainforest), $53.5 \%$ (Guinea savanna) and $54.9 \%$ (derived savanna) previously reported by Adedokun and Sonaiya (2001) for local chickens collected from those agroecologies and raised intensively. Birds in this study were raised under the semi-scavenging system of production. The difference in the two results could be due to the different management systems adopted. The semi-scavenging/semi-intensive systems, in which feed quality and quantity are subject to farmers' ability to provide supplementary feed and the amount of scavengeable feed resource (SFRs) available (Sonaiya, 2004), may explain some of the variations in the HDEP observed in this study. Jacob et al. (2017) have asserted that egg

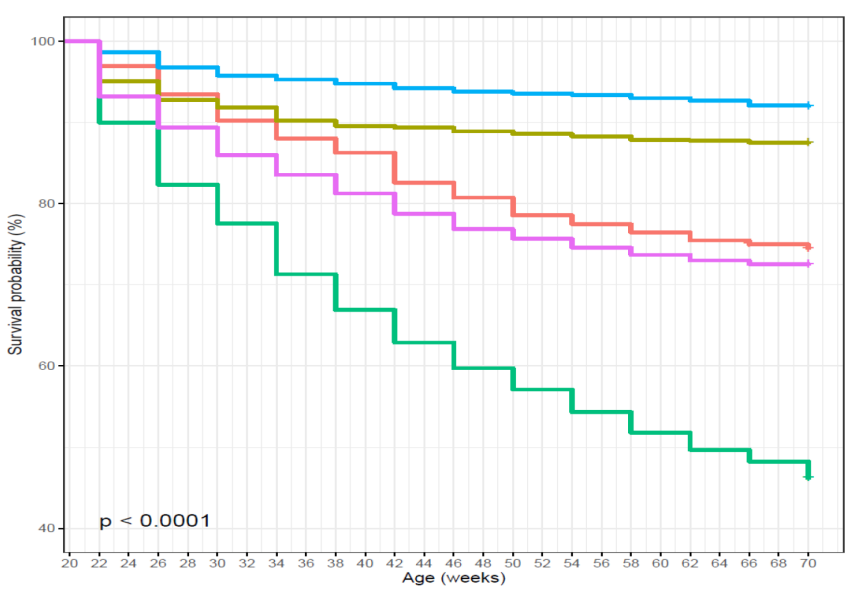

STATE - IMO -

Figure 10. Effect of agroecology on survival performance of female birds raised on-farm in ACGG Nigeria project zones (20-72 weeks) (2016-2018).

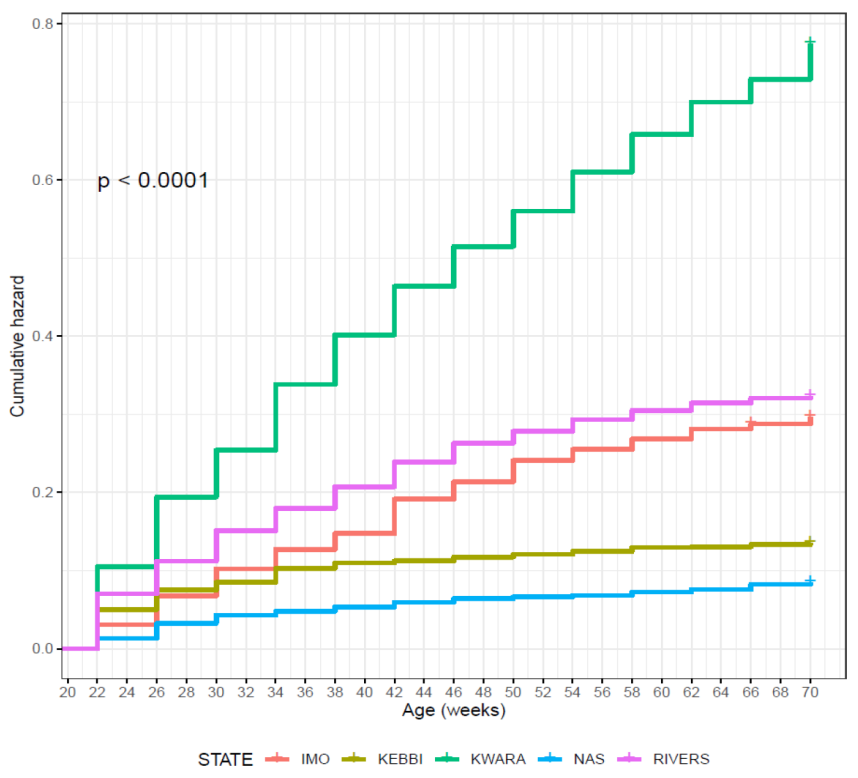

Figure 11. Effect of agroecology on cumulative hazard of female birds raised on-farm in ACGG Nigeria project zones (20-72 weeks) (2016-2018).

production in backyard chicken flocks is affected by management and environmental factors, especially temperature, sometimes causing a sudden drop in egg production. During the laying phase the six chicken breeds also maintained a relatively uniform weight as revealed by the lower $\mathrm{CV}$ recorded at this period than what obtains in the growing phase. ShikaBrown had the highest HDEP. This was expected as ShikaBrown is more of an egg-type genotype than dual-purpose. FUNAAB Alpha ranked second in HDEP. Egg number had previously been reported as one of the significant traits influencing farmers' breed preference (Yakubu et al., 2019). The 

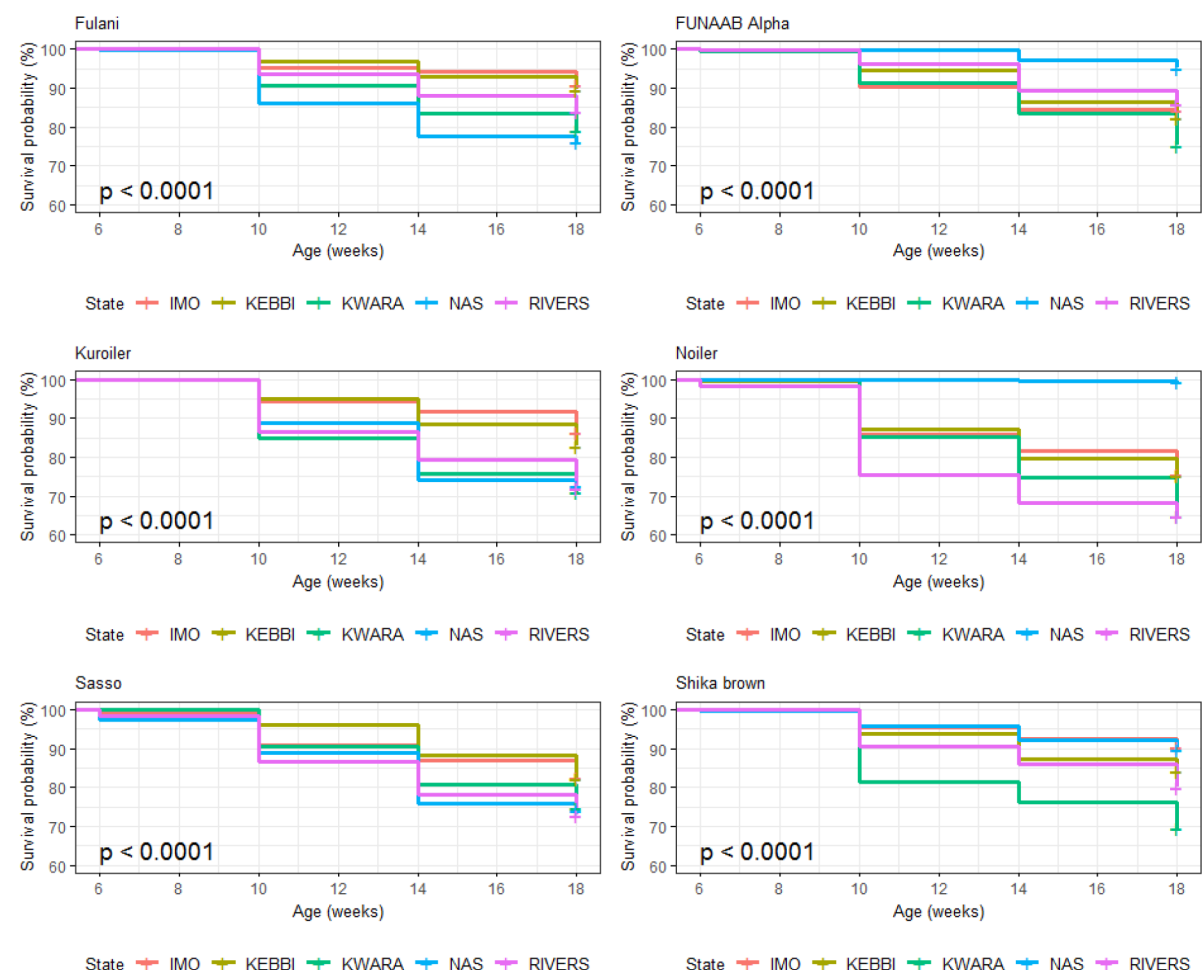

Figure 12. Breed by environment interaction on overall survivability of birds (breeds) during growing phase in ACGG Nigeria project zones (6-18 weeks) (2016-2017).
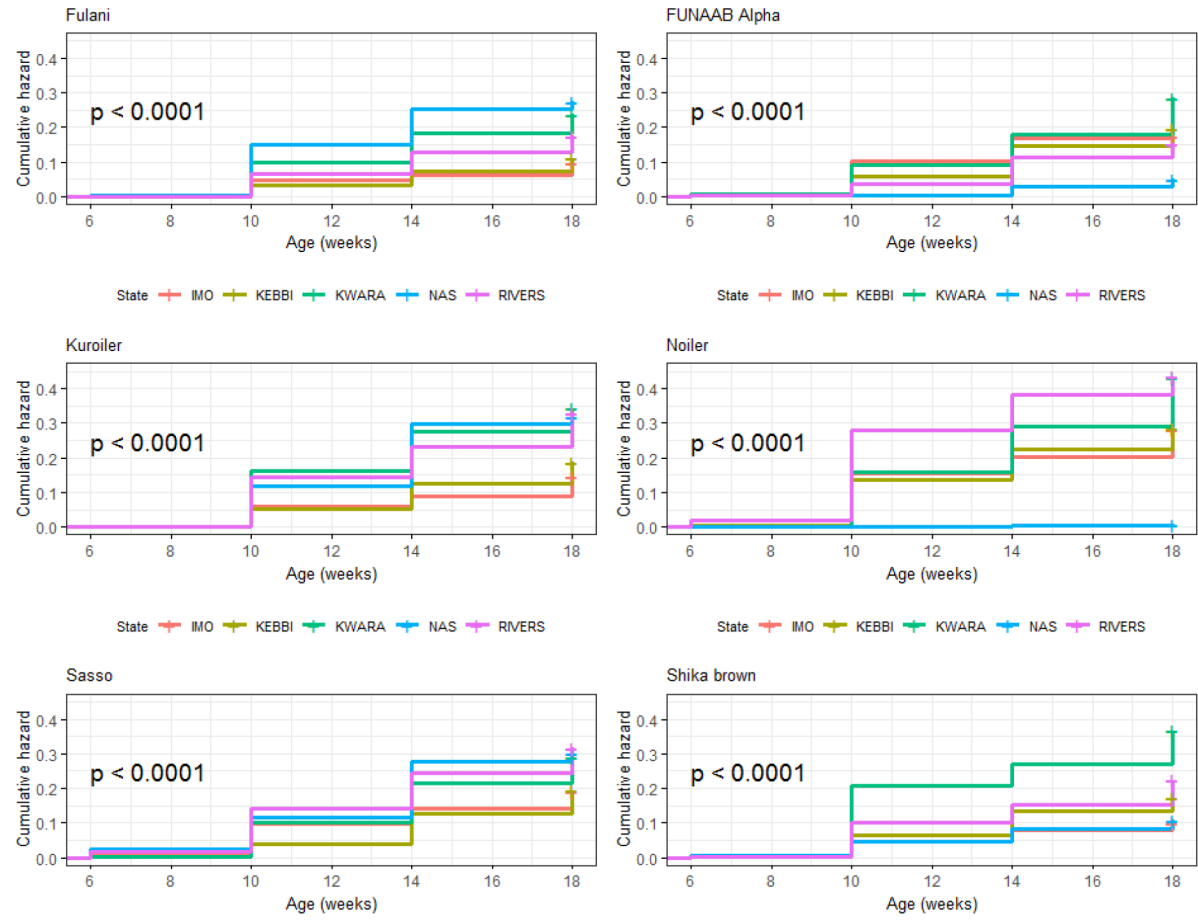

State + MMO + KEBBI + KWARA + NAS + RNERS

State + MNO + KEBBI + KWARA + NAS + RIVERS

Figure 13. Breed by environment interaction on cumulative hazard of birds (breeds) during growing phase in ACGG Nigeria project zones (6-18 weeks) (2016-2017). 

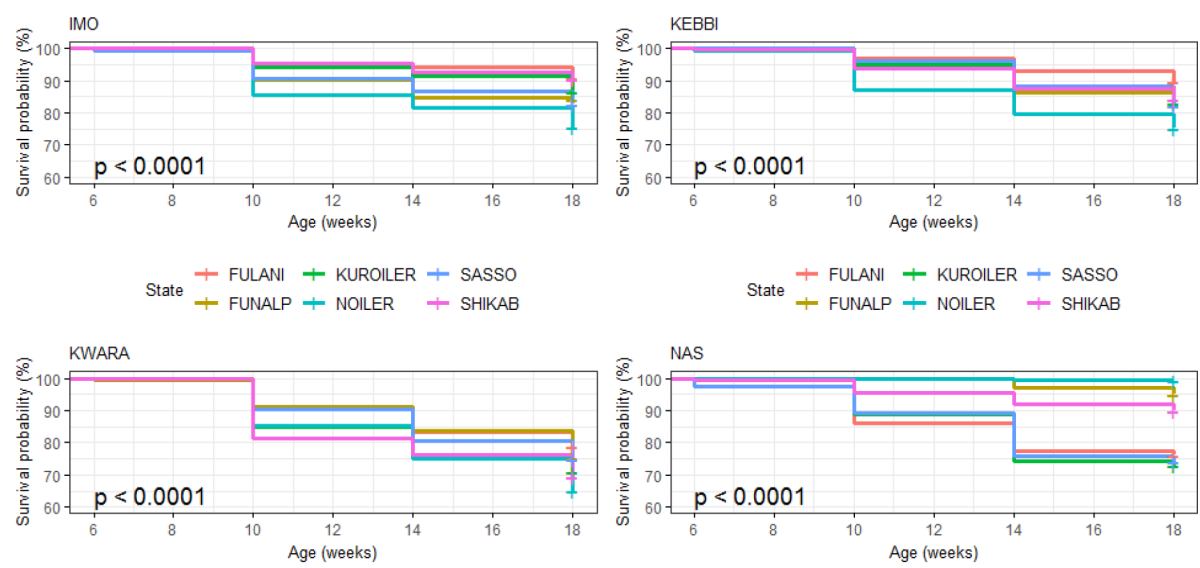

$$
\begin{aligned}
& \text { + FULANI + KUROILER + SASSO } \\
& \text { - FUNALP + NOILER }+ \text { SHIKAB }
\end{aligned}
$$$$
\begin{aligned}
& \text { + FULANI }+ \text { KUROILER }+ \text { SASSO } \\
& \text { State FUNALP }+ \text { NOILER }+ \text { SHIKAB }
\end{aligned}
$$

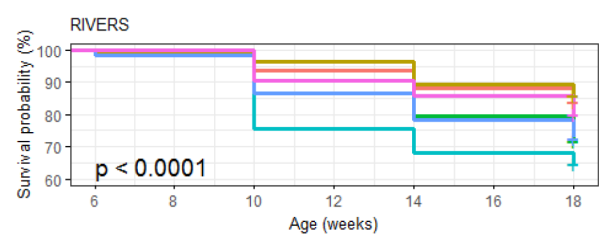

$$
\begin{aligned}
& \text { State }+ \text { FULANI }+ \text { KUROILER }+ \text { SASSO } \\
& \text { - FUNALP }+ \text { NOILER }+ \text { SHIKAB }
\end{aligned}
$$

Figure 14. Breed by environment interaction on overall survivability of birds (agroecologies) during growing phase in ACGG Nigeria project zones (6-18 weeks) (2016-2017).
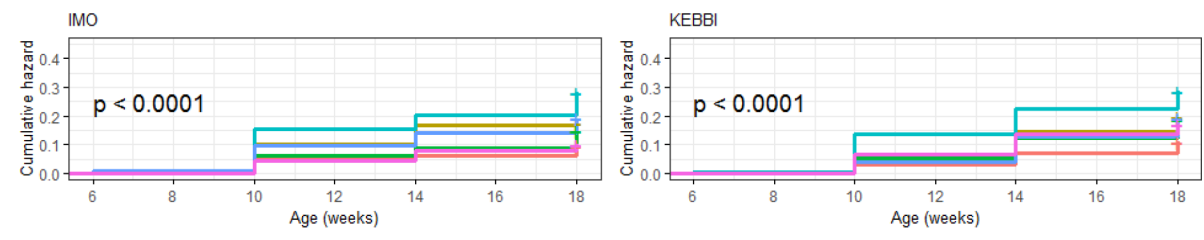

$$
\begin{aligned}
& + \text { FULANI }+ \text { KUROILER }+ \text { SASSO } \\
& \text { State }+ \text { FUNALP }+ \text { NOLLER }+ \text { SHIKAB }
\end{aligned}
$$

$$
\begin{aligned}
& + \text { FULANI }+ \text { KUROLLER }+ \text { SASSO } \\
& \text { State }+ \text { FUNALP }+ \text { NOLIER }+ \text { SHIKAB }
\end{aligned}
$$
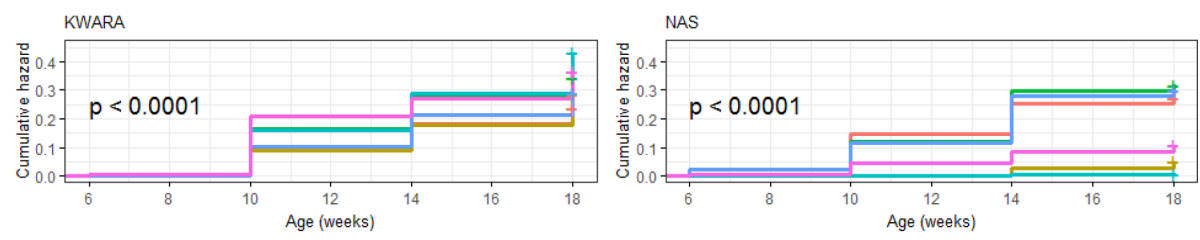

$$
\begin{aligned}
& \text { State FULANI + KUROLLER + SASSO } \\
& + \text { FUNALP }+ \text { NOLLER }+ \text { SHIKAB }
\end{aligned}
$$

State + FULANI + KUROLlER + SASSO

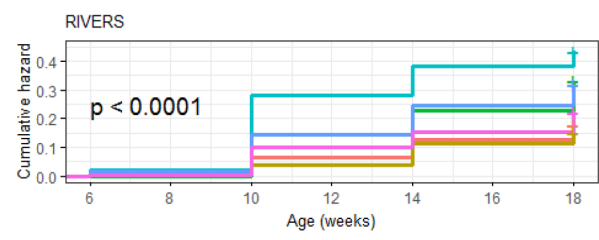

State - FUNALP + NOLLER — SHIKAB

$$
\text { State }+ \text { FULANI }+ \text { KUROILER }+ \text { SASSO }
$$

Figure 15. Breed by environment interaction on overall cumulative hazard of birds (agroecologies) during growing phase in ACGG Nigeria project zones (6-18 weeks) (2016-2017). 

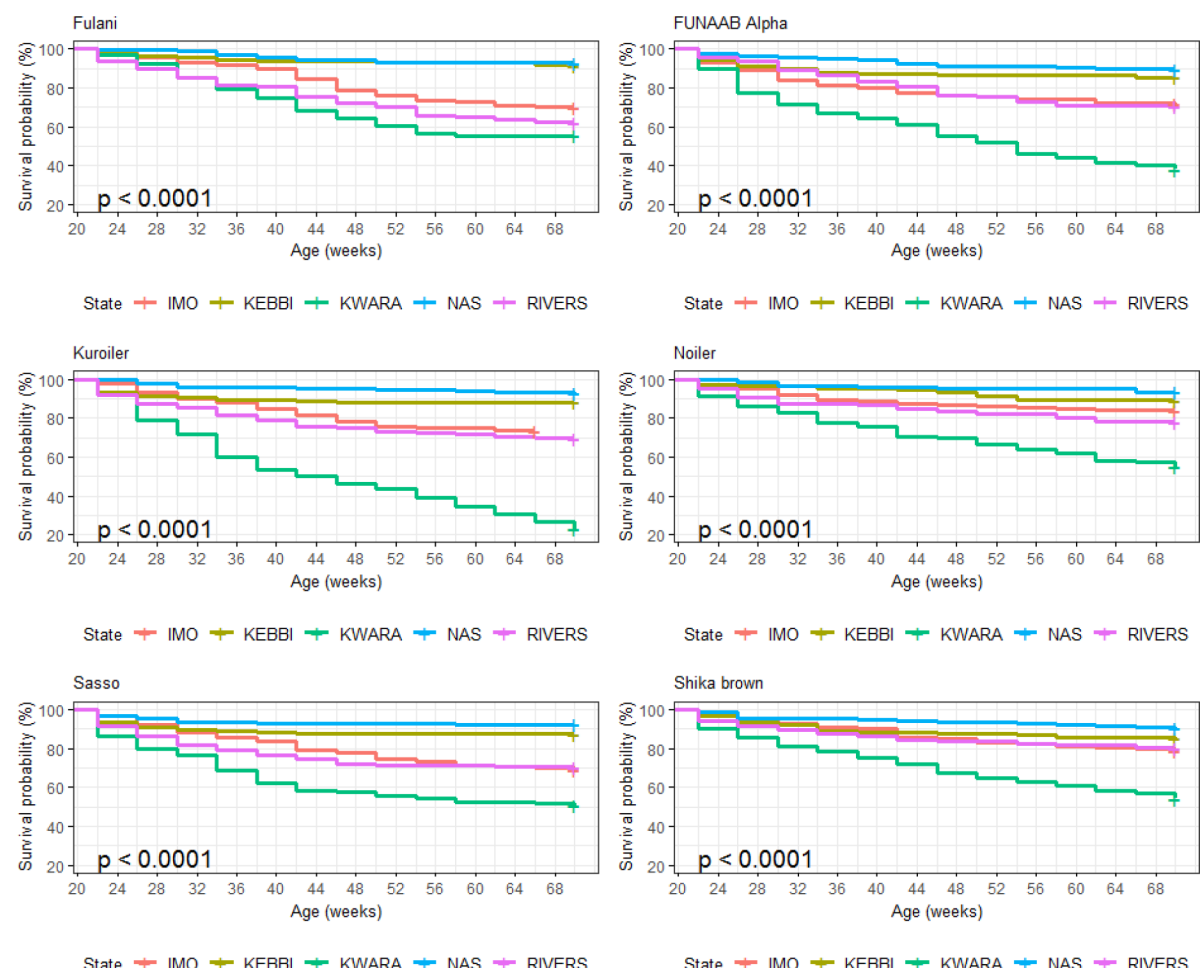

Figure 16. Breed by environment interaction on survivability of female birds (breeds) raised on-farm in ACGG Nigeria project zones (20-72 weeks) (2016-2018).
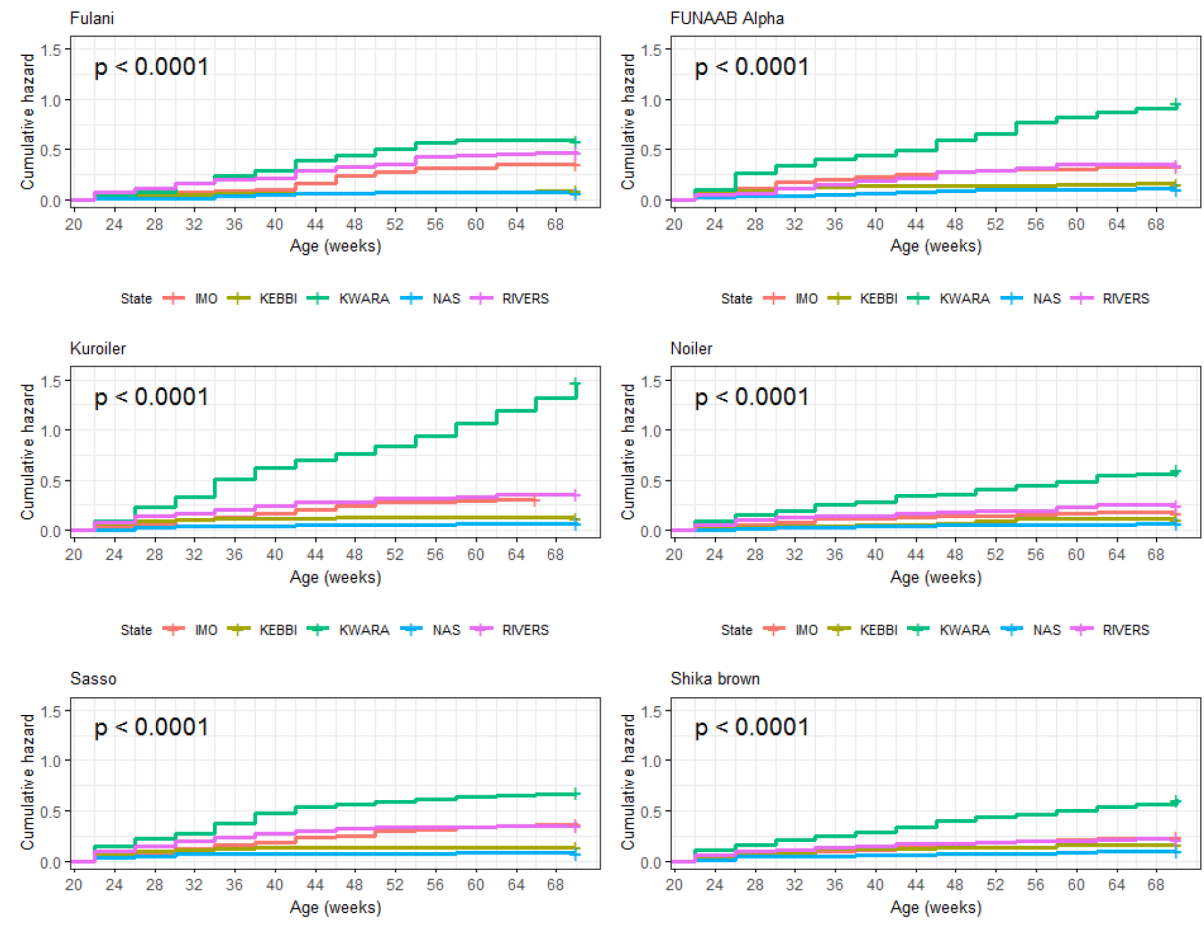

State $-1 M O+$ KEBBI + KWARA + NAS + RIVERS

State + MMO - KEBBI + KWARA - NAS + RIVERS

Figure 17. Breed by environment interaction on cumulative hazard of female birds (breeds) raised on-farm in ACGG Nigeria project zones (20-72 weeks) (2016-2018). 

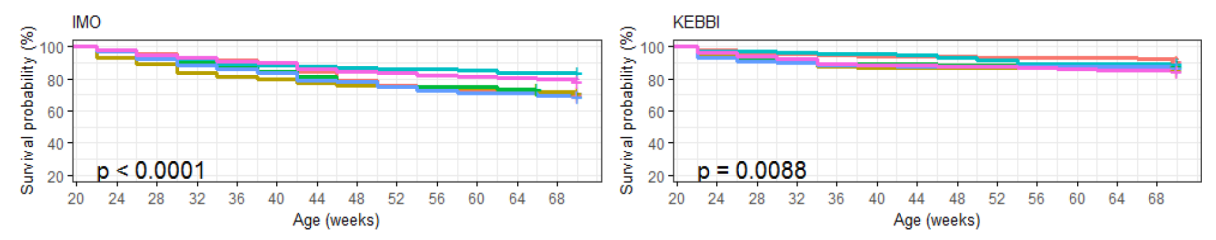

+ FULANI + KUROILER + SASSO
State
+ FUNALP + NOILER + SHIKAB

State + FULANI + KUROILER + SASSO
+ FUNALP + NOILER + SHIKAB
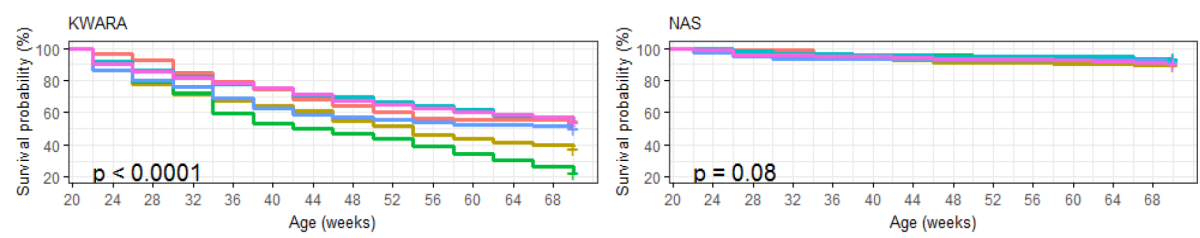

+ FULANI + KUROILER + SASSO
- FUNALP + NOILER + SHIKAB

- FULANI + KUROILER + SASSO
+ FUNALP + NOILER + SHIKAB

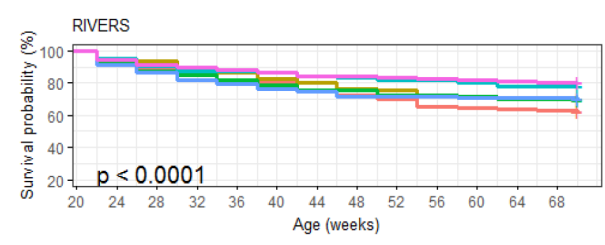

- FULANI + KUROILER + SASSO
State - FUNALP - NOIIER + SHIKAB

Figure 18. Breed by environment interaction on survivability of female birds (agroecologies) raised on-farm in ACGG Nigeria project zones (20-72 weeks) (2016-2018).
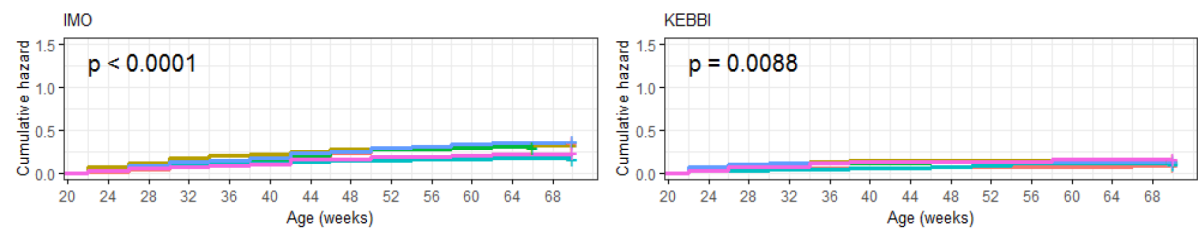

$$
\begin{aligned}
& \text { + FULANI }+ \text { KUROLLR }+ \text { SASSO } \\
& + \text { FUNALP }+ \text { NOLLER }+ \text { SHIKAB }
\end{aligned}
$$$$
\begin{aligned}
& \text { - FULANI }+ \text { KUROILER }+ \text { SASSO } \\
& \text { State }+ \text { FUNALP + NOILER }+ \text { SHIKAB }
\end{aligned}
$$
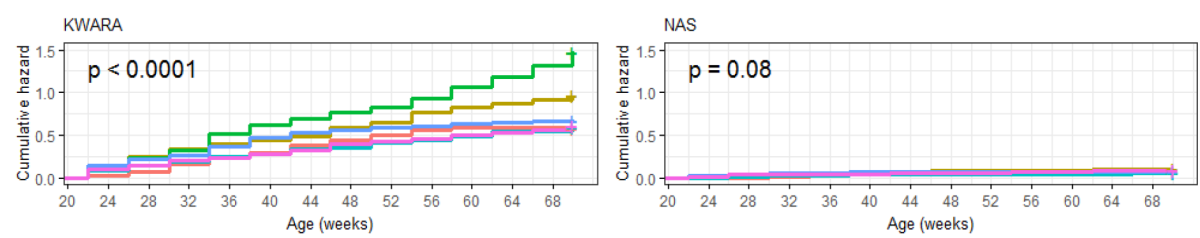

$$
\begin{aligned}
& \text { State FULANI }+ \text { KUROLLER }+ \text { SASSO } \\
& + \text { FUNALP }+ \text { NOLLER }+ \text { SHIKAB }
\end{aligned}
$$$$
\begin{aligned}
& \text { - FULANI + KUROILER + SASSO } \\
& \text { State FUNALP + NOILER }+ \text { SHIKAB }
\end{aligned}
$$

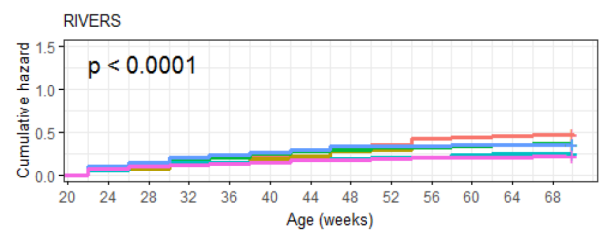

$$
\text { State }+ \text { FULANI }+ \text { KUROLLR }+ \text { SASSO }
$$

Figure 19. Breed by environment interaction on cumulative hazard of female birds raised on-farm in ACGG Nigeria project zones (2270 weeks) (2016-2018). 
average egg weight of the six breeds of chicken was higher by $146 \%$ compared to the $35 \mathrm{~g}$ reported for the local eggs (Adedokun and Sonaiya, 2002; Ajayi, 2010).

\subsection{Survival probability and hazard risk factors associated with birds}

Actual mortality did not include birds sold or consumed by the household or lost to predators. The overall mortality rate during growing and laying phases was highest in Kwara (derived savanna) and lowest in Imo (lowland forest). Tadesse (2014) reported higher mortality and lower survival of chicks in lowland than in midland agroecologies in northern Ethiopia.

The high mortality rate recorded between 6 and 18 weeks of age coincided with the period of peak rainfall that favours the spread of various disease pathogens in the tropics. Average daily temperature and relative humidity ranged from $26.4^{\circ} \mathrm{C}$ (Imo) to $28.4^{\circ} \mathrm{C}$ (Nasarawa) and $74.0 \%$ (Nasarawa) to $80.0 \%$ (Imo), respectively. Talukder et al. (2010) reported that high temperature and high humidity may negatively affect the growth and physiology of birds. Compared with Kuroiler, Noiler and Sasso, the higher survivability of FUNAAB Alpha, Fulani and Shika-Brown may be attributed to their adaptability to the prevailing environmental conditions (Yakubu and Ari, 2018). Indigenous chickens possess higher natural antibodies that aid their survival (Wondmeneh et al., 2015) and adaptability (Sankhyan and Thakur, 2018) in the extensive production system.

Fulani, an indigenous strain commonly found within the kraals of nomadic Fulanis, showed the highest survivability in all the five agroecologies. A higher probability of mortality for Kuroiler, Sasso and Noiler in the growing phase could be indicative of the need for good management of the birds to minimize stressful conditions in the early growing phase. According to Shittu et al. (2014), hot dry seasons that coincide with the months of February to May have been indicated for a spike in mortality with reduced egg production in laying hens raised in northwest Nigeria.

\section{Conclusion}

The results from this study showed that all the breeds had superior growth and laying performance compared to the local chickens. The group of Kuroiler, Sasso and Noiler had higher male body weight compared to FUNAAB Alpha, Shika-Brown and Fulani. The HDEP for Shika-Brown, FUNAAB Alpha and Kuroiler was higher than for Fulani, Noiler and Sasso, while Kuroiler and Sasso had higher egg weights. Ranking of the breeds (from highest to lowest) in terms of growth, laying performance and survivability was as follows: Shika-Brown/Sasso, FUNAAB Alpha/Noiler, Kuroiler and Fulani. The agroecological zones most suitable for the production and performance of the breeds, under the backyard scavenging management system, were ranked (from high- est to lowest) as follows: wet lowland rainforest and freshwater swamp (Imo State), Sudan and northern Guinea savanna (Kebbi State), derived and southern Guinea savanna (Nasarawa State), mangrove swamp and freshwater swamp (Rivers State), and southern Guinea and northern Guinea savanna (Kwara State). The findings from this study show the potential of improved, dual-purpose breeds for increased smallholder poultry production.

\section{Ethics approval and consent to participate}

The ethical guidelines were approved by International Livestock Research Institute (ILRL-IREC2015-08/1).

Data availability. All raw data are available as open access at http: //data.ilri.org/portal/dataset/acggonfarmng (Dessie et al., 2017).

Author contributions. Conceptualization of the research work and the methodology were done by EBS and OB. Data curation and investigation were carried out by OOA, FOA, AY, UEO, WAH, OB, EBS and OAA. Formal analysis was achieved by OMA, OB and EBS. The original draft was written by FOA. Writing, review and editing was accomplished by FOA, AY, OB, EBS and OAA.

Competing interests. The authors declare that they have no conflict of interest.

Acknowledgements. The authors gratefully acknowledge the financial support of the Bill and Melinda Gates Foundation and technical assistance from ILRI, the coordinating centre for the project.

Financial support. This research has been supported by the Bill $\&$ Melinda Gates Foundation (grant no. OPP1112198).

Review statement. This paper was edited by Manfred Mielenz and reviewed by Moses Okpeku and one anonymous referee.

\section{References}

Adedokun, S. A. and Sonaiya, E. B.: Comparison of the performance of Nigerian indigenous chickens from three agroecological zones, Livestock Research for Rural Development, 13, 15, available at: http://www.lrrd.org/lrrd13/2/aded132.htm (last access: 26 August 2020), 2001.

Adedokun, S. A. and Sonaiya, E. B.: Crossbreeding Nigeria indigenous with the Dahlem Red chickens for improved productivity and adaptability, Archiv. Tierzucht Dummerstorf, 45, 297-305, 2002.

Ajayi, F. O.: Nigerian indigenous chicken: A valuable genetic resource for meat and egg production, Asian J. of Poultry Science, 4, 164-172, 2010. 
Ajayi, F. O. and Agaviezor, B. O.: Fertility and hatchability performance of pure and crossbred indigenous chicken strains in the high rainforest zone of Nigeria, International Journal of Livestock Production, 7, 141-144, 2016.

Alabi, O. O., Ajayi, F. O., Bamidele, O., Yakubu, A., Ogundu, E. U., Sonaiya, E. B., Ojo, M. A., Hassan, W. A., and Adebambo, O. A.: Impact assessment of improved chicken genetics on livelihoods and food security of smallholder poultry farmers in Nigeria, Livestock Research for Rural Development, 32, 77, available at: http://www.lrrd.org/lrrd32/5/alabi32077.html, last access: 26 August 2020.

Alemayehu, T., Bruno, J., Getachew, F., and Dessie, T.: Socioeconomics, marketing and gender aspects of village chicken production in the tropics: A review of literature, International Livestock Research Institute (ILRI) Project Report, Nairobi, Kenya, 2018.

Bamidele, O., Sonaiya, E. B., Adebambo, O. A., and Dessie, T.: On-station performance evaluation of improved tropically adapted chicken breeds for smallholder poultry production systems in Nigeria, Trop. Anim. Health Pro., 52, 1541-1548, https://doi.org/10.1007/s11250-019-02158-9, 2019.

Billah, S. M., Nargis, F., Hossain, M. E., Howlider, M. A. R., and Lee, S. H.: Family poultry production and consumption patterns in selected households of Bangladesh, Journal of Agricultural Extension and Rural Development, 5, 62-69, 2013.

Dessie, T., Assefa, G., Esatu, W., Abegaz, S., Hamisi, E., Mbaga, S., Shayo, D., Sonaiya, F., Bamidele, O., Adebambo, O., Adeyinka, I., Komen, H., Jaramillo, M., Rege, E., Ouma, R., Mujiibi, D., Hanotte, O., Bruno, J., Alemayehu, T., Getachew, F., Kassaye, H., Njamba, H., and Poole, J.: African Chicken Genetic Gains (ACGG) on-farm data for Nigeria, available at: http://data.ilri. org/portal/dataset/acggonfarmng (last access: 17 April 2018), 2017.

Falconer, D. S. and Mackay, T. F. C.: Introduction to Quantitative Genetics, 4th Edn., Longman, London, UK, 1996.

Fox, J. and Weisberg, S.: An R Companion to Applied Regression, 2nd Edition, Thousand Oaks CA, Sage, 2011.

Garcês, A., Casey, N. H., and Horst, P.: Productive performance of naked neck, frizzle and dwarf laying hens under various natural climates and two nutritional treatments, S. Afr. J. Anim. Sci., 31, 174-180, 2001.

Guèye, E. F.: The role of family poultry in poverty alleviation, food security and the promotion of gender equality in rural Africa, Outlook Agr., 29, 129-136, 2000.

Hassan, W. A., Yakubu, A., Bamidele, O., Ajayi, F. O., Ogundu, U. E., Alabi, O., Sonaiya, E. B., and Adebambo, O. A.: Genetic differences in performance of five chicken genotypes reared in five sub-national zones in Nigeria, Proceedings of the 43rd Annual Conference of the Nigerian Society for Animal Production, Federal University of Technology, 18-22 March 2018, Owerri, Nigeria, 2018.

Hothorn, T., Bretz, F., and Westfall, P.: Simultaneous inference in general parametric models, Biometrical J., 50, 346-363, 2008.

Jacob, J. P., Wilson, H. R., Miles, R. D., Butcher, G. D., and Ben Mather, F.: Factors affecting egg production in backyard chicken flocks, U.S. Department of Agriculture, UF/IFAS Extension Service, University of Florida, IFAS, Florida A \& M University Cooperative Extension Program, and Boards of County Commissioners Cooperating, Nick T. Place, dean for UF/IFAS Extension,
Publication PS 35, available at: https://edis.ifas.ufl.edu/ps029 (last access: 30 September 2019), 2017.

Kassambara, A. and Kosinski, M.: Survminer, drawing survival curves using gplot2, R package, version 0.4.4, available at: https://CRAN.Rproject.org/package=survminer, last access: 30 September 2019.

Kitalyi, A. J.: Village chicken production systems in rural Africa, household food security and gender issues, The Food and Agriculture Organization, Rome, Italy, 1998.

Kryger, K. N., Thomsen, K. A., Whyte, M. A., and Dissing, M.: Smallholder poultry production: livelihoods, food security and sociocultural significance, FAO Smallholder Poultry Production Paper, 4, Rome, Italy, 2010.

Length, R. V.: Least-squares means: The R Package Least Square Means, J. Stat. Softw., 69, 1-33, https://doi.org/10.18637/jss.v069.i01, 2016.

Mellese, A.: Significance of scavenging chicken production in the rural community of Africa for enhanced food security, World Poultry Science Journal, 70, 593-606, https://doi.org/10.1017/S0043933914000646, 2014.

Nauta, W. J.: Selective breeding in organic dairy production, $\mathrm{PhD}$ thesis, Wageningen University, the Netherlands, 160 pp., 2009.

Nwosu, C. C.: Characterization of the local chicken of Nigeria and its potential for egg and meat production, Proceedings of $1 \mathrm{st} \mathrm{Na-}$ tional Seminar Poultry Production in Nigeria, edited by: Olomu, J. M., Offiong, S. A., Buvanedran, B., and Osinowo, O. O., Ahmadu Bello University, Zaria, 187-210, 1979.

Nwosu, C. C. and Asuquo, B. O.: Heritability and correlation estimates of body weight in the local chicken, in: Self-sufficiency in Animal Protein Supply Under Changing Economic Fortunes, edited by: Olomu, J. M., Ikhatua, U. J., Taiwo, A. A., and Jagun, A. G., Proceedings 19th Annual Conference of Nigeria Society of Animal Production, 20-26 March 1985, University of Benin, 49-56, 1985.

Olori, V. E. and Sonaiya, E. B.: Effect of length of lay of Nigeria indigenous chickens on their egg composition and shell quality, Nig. Journal Anim. Prod., 19, 95-100, 1992.

Oyewale, O. A., Ojebiyi, O. O., Adedeji, F. A., Bamidele, O., and Sonaiya, E. B.: A smallholder poultry feed app: development and field test, International Journal of Poultry Science, 19, 176-185, 2020.

R Core Team.: R: A language and environment for statistical computing, R Foundation for Statistical Computing, Vienna, Austria, available at: https://www.R-project.org/ (last access: 20 July 2019), 2018.

Roy, R., Monda, T., and Moktan, M. W.: Production performance of improved poultry under backyard farming system in hill agroclimatic condition in West Bengal, Indian Journal of Hill Farming, Special Issue, 21-26, 2017.

Sankhyan, V. and Thakur, Y. P.: Development and evaluation of location specific chicken variety for improving rural poultry farming in western Himalayan state of Himachal Pradesh, India, Proceedings of the World Congress on Genetics Applied to Livestock Production, Species - Avian 2, 87 pp., 2018.

Shittu, A., Raji, A. A., Madugu, S. A., Hassan, W. A., and Fasina, F. O.: Predictors of death and production performance of layer chickens in opened and sealed pens in a tropical savannah environment, BMC Vet. Res., 10, 214, https://doi.org/10.1186/s12917-014-0214-7, 2014. 
Sonaiya, E. B.: The context and prospects for development of smallholder rural poultry production in Africa, CTA-Seminar Proceedings on Smallholder Rural Poultry Production, 9-13 October 1990, Thessaloniki, Greece, 1, 35-52, 1990.

Sonaiya, E. B.: Technical parameters for the assessment of scavengeable feed resource for poultry, in: Improving farmyard poultry production in Africa: Interventions and their economic assessment, Proceedings of a final research coordination meeting organized by the Joint FAO/IAEA Division of Nuclear Techniques in Food and Agriculture, 24-28 May 2004, Vienna, 2004.

Sonaiya, E. B.: Family poultry, food security and the impact of HPAI, World's Poultry Sci. J., 63, 132-138, https://doi.org/10.1017/S0043933907001353, 2007.

Sorensen, P.: Chicken genetic resources used in smallholder production systems and opportunities for their development, FAO Smallholder Poultry Production Paper No. 5, FAO, Rome, 2010.

Tadesse, A.: Production and reproduction performance of rural poultry in lowland and midland agro-ecological zones of Central Tigray, Northern Ethiopia, British Journal of Poultry Sciences, 3, 6-14, 2014.

Talukder, S., Islam, T., Sarker, S., and Islam, M. M.: Effects of environment on layer performance, J. Bangladesh Agril. Univ, 8, 253-258, 2010.

Therneau, T.: A package for survival analysis in S. version 2.38, available at: https://CRAN.R-project.org/package=survival (last access: 20 August 2019), 2015.
Wondmeneh, E., Van Arendonk, J. A. M., Van der Waaij, E. H., Ducro, B. J., and Parmentier, H. K.: High natural antibody titers of indigenous chickens are related with increased hazard in confinement, Poultry Sci., 94, 1493-1498, 2015.

Yakubu, A. and Ari, M. M.: Principal component and discriminant analyses of body weight and conformation traits of Sasso, Kuroiler and indigenous Fulani chickens in Nigeria, J. Animal Plant Sci., 28, 46-55, 2018.

Yakubu, A., Salako, A. E., and Ige, A. O.: Effects of genotype and housing system on the laying performance of chickens in different seasons in the semi-humid tropics, International Journal of Poultry Science, 6, 434-439, 2007.

Yakubu, A , Bamidele, O., Hassan, W. A., Ajayi, F. O., Ogundu, U. E., Alabi, O. O., Sonaiya, E. B., and Adebambo, O. A.: Farmers' choice of genotypes and trait preferences in tropically adapted chickens in five agro-ecological zones in Nigeria, Trop. Animal Health Pro., 52, 95-107, https://doi.org/10.1007/s11250019-01993-0, 2019.

Yusuf, S. F. G., Lategan, F. S., and Masika, P. J.: Characterization of indigenous poultry production systems in the Nkonkobe $\mathrm{Mu}-$ nicipality, Eastern Cape Province South Africa, J. Agr. Sci., 5, 31-44, 2014. 